\title{
O ATLÂNTICO SUL NOS DISCURSOS NA ONU: UMA ANÁLISE DE CONTEÚDO SOBRE O CARÁTER REGIONAL DO ESPAÇO OCEÂNICO (1986-2015)
}

\author{
THE SOUTH ATLANTIC OCEAN IN THE DISCOURSES AT THE UN: A CONTENT \\ ANALYSIS ON THE REGIONAL NATURE OF THE OCEANIC SPACE (1986-2015)
}

Douglas Henrique Novelli ${ }^{1}$

Alexsandro Eugenio Pereira ${ }^{2}$

\begin{abstract}
Resumo
A presente pesquisa se insere junto a estudos sobre construção de regiões, entendidas aqui como construções cognitivas atreladas a projetos políticos e manifestadas por meio de discursos. Trabalhos nessa mesma linha teórica já foram desenvolvidos sobre o Atlântico Sul no passado, mas sempre limitados à perspectiva da política externa brasileira enquanto potencial agente construtor da região sul-atlântica, ignorando a resposta dos demais Estados ao projeto. Procurando sanar essa lacuna, a pesquisa aplicou o método da análise de conteúdo quantitativa a 106 discursos que contivessem citações ao Atlântico Sul, proferidos na Assembleia Geral das Nações Unidas por Estados banhados pelo oceano em questão. O conteúdo dos textos foi categorizado dentro de cinco dimensões de análise: (1) delimitação geográfica; (2) relações políticas internacionais ou transnacionais no território em questão que sejam descritas por seus atores como dinâmicas regionais; (3) fatores identitários; (4) citação nominal a outros atores e; (5) questões pontuais tratadas como relevantes para o espaço em questão. Os resultados sugerem que a ZOPACAS de fato se trata de um projeto de construção regional para o Atlântico Sul, cujo período de maior força se deu entre 1986 e 1994, perdendo fôlego até 1998 e caindo no ostracismo desde então. Embora a retomada da iniciativa em 2007 tenha sinalizado um potencial renascimento de um projeto de construção regional sulatlântico, tudo indica que o espaço oceânico comum continua sendo interpretado majoritariamente como um mero espaço de interação entre as regiões da América do Sul e da África Ocidental.
\end{abstract}

Palavras-Chave: Atlântico Sul; ZOPACAS; Construção Regional.

\begin{abstract}
This research is related to studies about the building of regions, understood here as cognitive constructions linked to political projects and manifested through speeches. Studies in this same theoretical line have already been developed about the South Atlantic Ocean in the past, but always limited to the perspective of Brazilian foreign policy as a potential region-building agent of the South Atlantic region, ignoring the response of other states to the project. Seeking to remedy this gap, the research applied the method of quantitative

\footnotetext{
${ }_{1}^{1}$ Doutorando em Ciência Política pela Universidade Federal do Paraná (UFPR) e membro do Núcleo de Pesquisa em Relações Internacionais (NEPRI/UFPR). E-mail: douglashnovelli@outlook.com. ORCID: https://orcid.org/0000-0001-6058-5109.

2 Doutor em Ciência Política pela Universidade de São Paulo (USP), professor associado do Programa de Pós-Graduação em Ciência Política da Universidade Federal do Paraná (UFPR) e coordenador do Núcleo de Pesquisa em Relações Internacionais (NEPRI/UFPR). E-mail: alexsep@uol.com.br. ORCID: https://orcid.org/0000-0002-9613-4702.
} 
content analysis to 106 speeches containing citations to the South Atlantic, issued at the General Assembly of the United Nations by states bordered by the South Atlantic. The content of the texts was categorized into five analytical dimensions: (1) geographical delimitation; (2) international or transnational political relations in the territory in question that are described by their actors as regional dynamics; (3) identity factors; (4) nominal citation to other actors and; (5) specific issues treated as relevant to the space in question. The results suggest that ZOPACAS is, in fact, a region-building project for the South Atlantic Ocean, whose period of greatest strength took place between 1986 and 1994, losing steam until 1998 and falling into ostracism since then. Although the revival of the initiative in 2007 signaled a potential renaissance of a South-Atlantic regionbuilding project, it seems that the common oceanic space continues to be mostly interpreted as a mere area of interaction between the regions of South America and West Africa.

Keywords: South Atlantic; ZOPACAS; Region-Building.

\section{INTRODUÇÃO}

Em 2016 a Zona de Paz e Cooperação do Atlântico Sul (ZOPACAS) completou 30 anos de existência. Estabelecida em 1986 por meio da Resolução 41/11 da Assembleia Geral das Nações Unidas (AGNU), a ZOPACAS foi criada por iniciativa brasileira, com o objetivo expresso de promover a cooperação para o progresso social e econômico, a paz e a segurança no território oceânico comum e prevenir a introdução de armamentos nucleares e outros artefatos de destruição em massa no Atlântico Sul. Gradualmente esvaziada ao longo da década de 1990, a ZOPACAS foi retomada em 2007 por iniciativa angolana, com o país africano sediando a sexta reunião da Zona no mesmo ano, a qual seria seguida pela sétima reunião em 2013, ocorrida em Montevidéu, Uruguai. Esse aparente reavivamento da iniciativa foi responsável por promover um súbito aumento do interesse acadêmico sobre a pauta, com estudiosos das Relações Internacionais e áreas correlatas apresentando uma série de estudos que tratam das dinâmicas de segurança e cooperação para o desenvolvimento e paz associadas tanto ao território sul atlântico como um todo, quanto a ZOPACAS propriamente dita (para exemplos, ver: Aguilar, 2013; Amorim, 2013; Fernandes, 2015; Pimentel, 2016; Vaz e Migon, 2013; Viegas Filho, 2016; Wiesebron, 2013), em um movimento que se mantém ativo, mesmo que em menor escala, até o fim da década de 2010 (para exemplos recentes, ver: Carvalho e Souza, 2019; Espach, 2019).

Embora a maior parte desses trabalhos se proponha a estudar as dinâmicas associadas ao Atlântico Sul e a ZOPACAS pelo prisma da segurança, sobretudo através do framework teórico proposto pela chamada Escola de Copenhague e especialmente no que tange a Teoria dos Complexos Regionais de Segurança (Buzan, Wæver e Wilde, 1998; Buzan e Wæver, 2003), dois trabalhos se destacam precisamente por fugir desta abordagem: o artigo "O Brasil e a cooperação em defesa: a construção de uma identidade regional no Atlântico Sul”, de Adriana Abdenur e Danilo de Souza Neto, publicado em 2014 na Revista Brasileira de Política Internacional; e a dissertação 
de Luísa Calvete Portela Barbosa, intitulada "A Zona de Paz e Cooperação do Atlântico Sul (ZPCAS): Criação, Projeção e Dimensão Político-Estratégica", apresentada em 2015 no programa de Estudos Estratégicos Internacionais da UFRGS. O argumento dos dois trabalhos é semelhante, partindo das teses de construção regional propostas por Iver Neumann $(1994,2003)$ para defender a hipótese de que a ZOPACAS se trata da "materialização de um discurso, cujo objetivo é busca por autonomia e autodeterminação da região sul-atlântica por parte de seus integrantes" (Barbosa, 2015, p. 16), sendo financiada em grande parte pelo governo brasileiro que, através dela, busca promover "a criação de uma identidade regional sul-atlântica, na qual o Brasil assegura para si uma posição de destaque" (Abdenur e Souza Neto, 2014, p. 6).

O presente artigo se insere junto aos últimos, igualmente adotando o framework proposto por Neumann para, através dele, analisar as dinâmicas no Atlântico Sul. Tomando como base os pressupostos originalmente apresentados por Benedict Anderson na obra Imagined Communities: Reflections on the Origin and Spread of Nationalism (1983), Neumann argumenta que regiões devem ser compreendidas como comunidades imaginadas, as quais são precedidas por atores que "como parte de algum projeto político, percebem como sendo de seu interesse imaginar uma certa identidade cronológica e espacial para uma área e disseminar tal ideia para o maior número de outras pessoas" (NEUMANN, 2003, p. 161, tradução nossa) ${ }^{3}$. Assim, como coloca Tassinari (2004, p. 56, tradução nossa), vistas sob o framework teórico proposto por Neumann, regiões "são essencialmente produto de atores políticos e criadas pelos discursos desses atores sobre a região"4.

Nesse sentido, a presente pesquisa se propõe a tentar desvendar a evolução do pensamento dos Estados banhados pelo Atlântico Sul - expresso através dos discursos de seus representantes - sobre o caráter regional do mesmo. Para atingir os objetivos propostos, o artigo se debruçará especificamente sobre os discursos sobre o Atlântico Sul proferidos pelos membros da ZOPACAS na AGNU entre os anos de 1986 e 2015. Tendo em vista que o banco de dados em questão está integralmente disponível para consulta pública e remete até o ano de fundação da ZOPACAS, o mesmo oferece uma vantagem analítica prática se comparado as demais arenas discursivas nas quais o Atlântico Sul foi pauta, incluindo as próprias reuniões ministeriais da ZOPACAS, oferecendo, assim, a melhor opção para uma análise diacrônica ampla e aprofundada como a que aqui será apresentada. Além disso, devemos também ressaltar que a própria ZOPACAS foi gestada na AGNU, tendo essa se mantido como o principal canal público de debate

\footnotetext{
${ }^{3}$ Texto Original: "They are political actors who, as part of some political project, see it in their interest to imagine a certain spatial and chronological identity for a region, and to disseminate this imagination to a maximum number of other people".

${ }^{4}$ Texto original: "regions are essentially a product of political actors and are created by actor-generated discourses on the region".
} 
sobre a pauta, ao menos no que se refere a suas duas primeiras décadas. Apesar disso, não foi possível localizar nenhum trabalho anterior que analise esse material, tornando o presente estudo particularmente relevante para a compreensão do Atlântico Sul enquanto uma região em potencial.

Na sequência, o artigo estará estruturado em duas seções principais, além desta introdução e das considerações finais. A primeira apresenta os métodos de coleta e análise dos dados. A segunda seção apresenta e discute os dados coletados nesta pesquisa.

\section{MÉTODOS}

\subsection{MÉTODOS DE COLETA E APRESENTAÇÃO DO CORPUS}

Os dados que compõe o corpus da pesquisa foram coletados por meio do Sistema de Bibliotecas Digitais das Nações Unidas (United Nations Digital Library), acessível através do link <https://digitallibrary.un.org>. A coleta de dados foi realizada no dia 07 de setembro de 2019, através da busca pela palavra-chave "South Atlantic" ${ }^{5}$, a qual resultou em um total de 177 discursos localizados entre os anos de 1986 e 2015 , todos no âmbito da AGNU. Visando ainda evitar distorções decorrentes da análise de idiomas distintos, a pesquisa adotou a opção metodológica de analisar exclusivamente os textos em inglês.

O Gráfico 1 expõe o volume total de discursos obtidos de acordo com o Estado responsável por expressá-los. O total de 177 discursos localizados divide-se entre 43 países. No Gráfico 1 optou-se por agrupar na categoria "outros" os discursos dos Estados que se pronunciaram sobre o tema apenas uma ou duas vezes no período recortado. Em um primeiro momento seis Estados despontam como os mais ativos nos debates sobre o Atlântico Sul no âmbito das Nações Unidas. Destes, o Brasil se destaca, tendo se manifestado um total de 24 vezes, $50 \%$ mais do que o segundo Estado mais ativo e representando $13,64 \%$ do total. Vale ainda ressaltar a participação de Nigéria, Argentina e Uruguai nos debates, totalizando juntos 42 discursos, o que representa $23,86 \%$ do total.

\footnotetext{
${ }^{5}$ A ZOPACAS é sempre referida por seu nome completo, Zone of Peace and Cooperation of the South Atlantic. Desse modo, as buscas pelo termo "South Atlantic" necessariamente retornam com todos as menções a ZOPACAS.

${ }^{6}$ Ressalta-se que não foram localizados quaisquer registros após 2015.
} 
GRÁFICO 1: DISCURSOS NA AGNU CONTENTO O TERMO “SOUTH ATLANTIC", PRONUNCIADOS ENTRE OS ANOS DE 1986 E 2015.

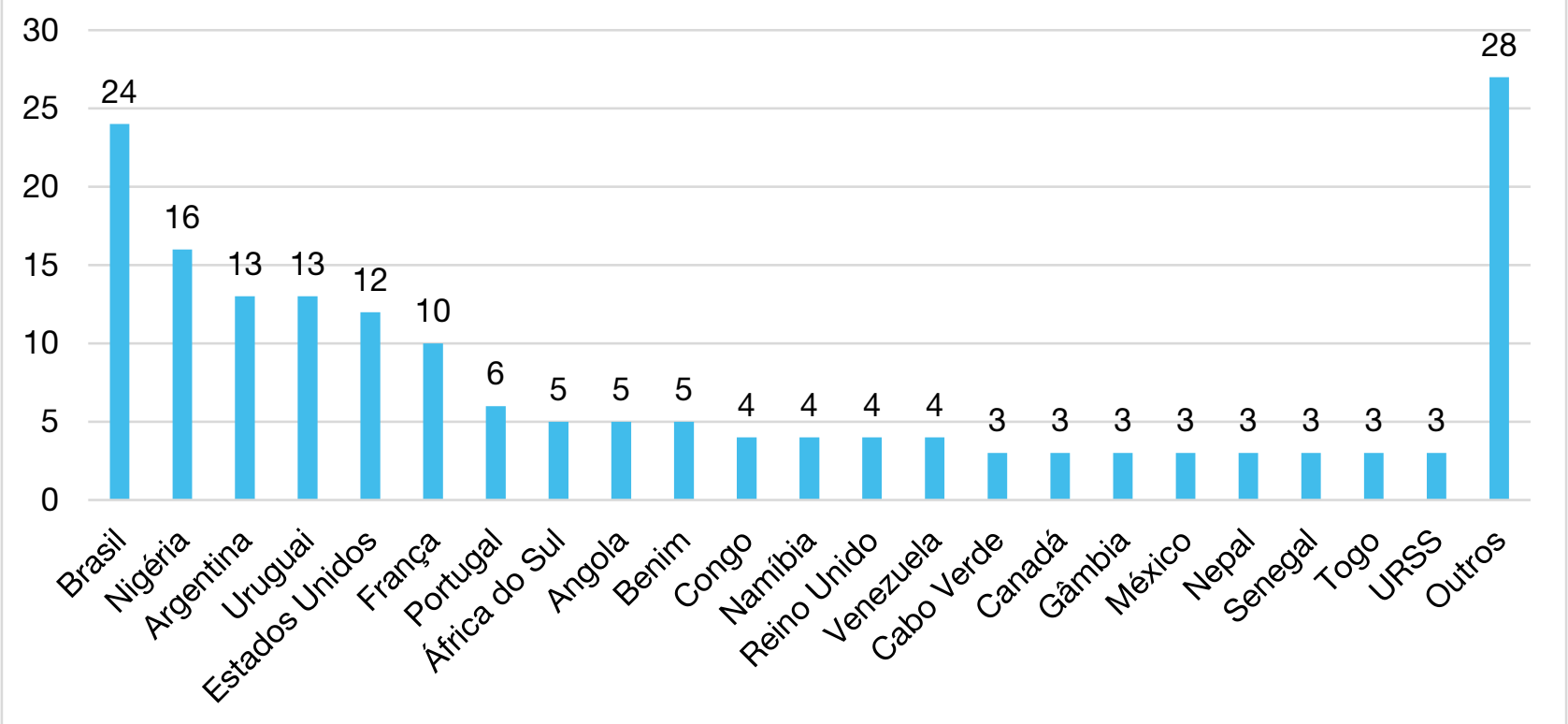

FONTE: Elaboração própria.

O Gráfico 1 também revela a intensa participação de Estados Unidos, França, Portugal e Reino Unido nos debates concernentes ao Atlântico Sul no âmbito da AGNU. Juntos, os quatro Estados representam aproximadamente $18,18 \%$ do total de manifestações localizadas. Contudo, embora se reconheça a relevância dos discursos destes Estados para o objeto de estudo em uma concepção ampla, eles não serão considerados no corpus da pesquisa. Essa exclusão se justifica, pois, sendo o objetivo da pesquisa desvendar se os Estados banhados pelo Atlântico Sul entendem esse território como uma região ou não, a análise aprofundada do discurso de Estados que não estão diretamente inseridos na região seria um desvio dos objetivos propostos.

Nesses termos, o recorte inicial se dará sobre os discursos proferidos pelos Estados banhados pelo Atlântico Sul. Serão considerados como tais apenas os 24 Estados-membros da ZOPACAS (África do Sul, Angola, Argentina, Benin, Brasil, Cabo Verde, Camarões, Congo, Costa do Marfim, Gabão, Gâmbia, Gana, Guiné-Conacri, Guiné-Bissau, Guiné-Equatorial, Libéria, Namíbia, Nigéria, República Democrática do Congo, São Tomé e Príncipe, Senegal, Serra Leoa, Togo e Uruguai), totalizando 106 discursos. Ressalta-se que na base de dados da ONU não consta qualquer pronunciamento com o termo "South Atlantic” por parte de sete destes Estados (Gabão, Guiné-Conacri, Guiné-Bissau, Guiné-Equatorial, Libéria, República Democrática do Congo e Serra Leoa). O número de pronunciamentos também varia consideravelmente, assim, a Tabela 1 apresenta o volume total de discursos de cada Estado, proferidos no âmbito da AGNU, que efetivamente integrarão o corpus da pesquisa. 
TABELA 1: DISCURSOS SOBRE O ATLÂNTICO SUL PROFERIDOS PELOS ESTADOS-MEMBROS DA ZOPACAS NA AGNU ENTRE 1986 E 2015.

\begin{tabular}{|ll|ll|}
\hline África do Sul (ZAF) & 5 & Gâmbia (GMB) & 3 \\
\hline Angola (AGO) & 5 & Gana (GHA) & 1 \\
\hline Argentina (ARG) & 13 & Namíbia (NAM) & 4 \\
\hline Benim (BEN) & 5 & Nigéria (NGA) & 16 \\
\hline Brasil (BRA) & 24 & São Tomé e Príncipe (STP) & 1 \\
\hline Cabo Verde (CPV) & 3 & Senegal (SEN) & 3 \\
\hline Camarões (CMR) & 1 & Togo (TGO) & 3 \\
\hline Congo (COG) & 4 & Uruguai (URY) & 13 \\
\hline Costa do Marfim (CIV) & 2 & & \\
\hline TOTAL & & & 106 \\
\hline
\end{tabular}

FONTE: Elaboração própria.

Concluída a apresentação dos dados que integram o corpus da pesquisa, avança-se agora para a apresentação dos métodos de análise que foram empregados.

\subsection{MÉTODOS DE ANÁLISE}

A pesquisa optou por adotar o método da análise de conteúdo quantitativa. De modo resumido, a análise de conteúdo trata-se de um conjunto de procedimentos que objetivam, através da manipulação das mensagens apresentadas nos textos, extrair indicadores que revelem os sentidos contidos nos documentos em questão, possibilitando estabelecer inferências por meio destes (Bardin, 2011, p. 52. Ver também: Campos, 2004, p. 611; Oliveira, 2008, p. 570). Esses procedimentos são melhor resumidos por Halperin e Heath, que elencam quatro passos básicos na aplicação das técnicas de análise de conteúdo: (1) definir os documentos relevantes para o corpus da pesquisa; (2) definir as variáveis que serão analisadas, assim como as categorias possíveis para cada variável; (3) estabelecer as unidades de registro que serão empregadas, isto é, quais parcelas do texto serão submetidas ao processo de categorização; e (4) criar um sistema de marcação que permita identificar no texto a presença das unidades de registro buscadas (Halperin e Heath, 2012, p. 320-322).

O primeiro destes passos já foi coberto na Seção 2.1, na qual foram detalhados os documentos que compõem o corpus da pesquisa - nomeadamente, discursos diretamente relacionados ao Atlântico Sul executados entre 1986 e 2015 pelos Estados-membros da ZOPACAS na Assembleia Geral da ONU - juntamente com as estratégias de coleta utilizados para obtê-los.

No que toca ao processo de categorização, recorremos ao artigo de Novelli e Pereira (2019) para estabelecer as variáveis que serão observadas. Nele, os autores apresentam um refinamento teórico das teses de construção regional propostas por Neumann (1994, 2003), sugerindo um modelo básico para a aplicação desse framework teórico em pesquisas empíricas, baseado na 
apresentação de quatro dimensões analíticas fundamentais ao se estudar processos de construção regional, sendo elas:

(1) Delimitação geográfica, que diz respeito ao território manifesto nos discursos como a dimensão física da região;

(2) Relações políticas internacionais ou transnacionais no território, as quais necessariamente devem ser expressas pelos mesmos como dinâmicas regionais em seus discursos;

(3) Fatores identitários, que essencialmente dizem respeito às regras de inclusão e exclusão expressas pelos atores em seus discursos para definir o que pertence ou não à região em questão; e

(4) Citação direta a outros atores, que observa pontos nos discursos nos quais um ator faz referência, geralmente positiva, à atuação de outro ator no potencial espaço regional.

Nesse sentido, é importante aqui destacar que o método da análise de conteúdo apresenta bases filosóficas distintas da análise de discurso empregada por Neumann $(1994,2003)$ nos trabalhos em que Novelli e Pereira (2019) se baseiam. A presente pesquisa, portanto, adota um viés mais descritivo em relação aos textos que compõem seu corpus, sendo esse característico da análise de conteúdo, recorrendo ao framework proposto por Novelli e Pereira (2019) como um guia base para o processo de categorização. Ademais, em adição ao modelo proposto pelos autores, incluiremos uma quinta dimensão de análise, a qual chamaremos de "questões pontuais apontadas como relevantes". Essa adição se faz necessária tendo em vista que, a partir da revisão dos próprios discursos analisados, foi possível constatar a presença de várias problemáticas que, embora não sejam tratadas como problemáticas regionais, mas sim como questões domésticas específicas a um ou dois Estados, ainda assim afetaram os discursos dos demais e parecem ter sido instrumentalizadas dentro do contexto de um projeto de construção regional sul-atlântico.

Em relação ao terceiro passo da análise de conteúdo, a pesquisa adotou um recorte de unidade de registro de nível semântico, o qual se dará em torno do tema, que nada mais é do que "a unidade de significação que se liberta naturalmente de um texto analisado segundo certos critérios relativos à teoria que serve de guia à leitura" (Bardin, 2011, p. 135). Nesses termos, se buscará nos discursos que compõem o corpus da pesquisa manifestações que apresentem correspondência com as cinco dimensões de análise anteriormente apresentadas e com suas respectivas categorias, as quais, por sua vez, serão derivadas dos próprios textos. A regra de 
enumeração será baseada na presença do tema em cada discurso, recortando-se trechos significativos para fins de categorização.

No que toca ao quarto e último passo identificado por Halperin e Heath (2012), isto é, a criação de um sistema de marcação que auxilie no processo de identificação das unidades de registro, foi optado pela utilização do software Atlas.ti, versão 7.5.7, o qual, embora seja primordialmente voltado para análise de dados em pesquisas qualitativas, fornece sólidos subsídios para a extração de dados quantitativos da amostra analisada. Assim, em um primeiro momento foram inseridos no programa todos os textos que compõem o corpus da pesquisa, passando, então, a leitura e categorização dos mesmos dentro do próprio software. Os dados quantitativos obtidos através da análise de conteúdo foram então extraídos do software, com a subsequente análise dos mesmos por meio de técnicas de estatística descritiva. A apresentação e discussão dos resultados obtidos será feita a seguir.

\section{ANÁLISE E APRESENTAÇÃO DOS RESULTADOS}

A seção a seguir será dedicada a análise e apresentação dos resultados do estudo proposto. Sua apresentação se dará por área temática, com cada conjunto de dados referentes às cinco dimensões de análise trabalhadas sendo apresentados em seções secundárias individuais.

Em um primeiro momento, a análise do volume de discursos proferidos no âmbito da AGNU permite observar a variação da relevância do Atlântico Sul enquanto pauta de debate internacional ao longo dos anos. O Gráfico 2 expõe a evolução do volume de discursos sobre o Atlântico Sul na ONU, considerando, para tanto, seu volume total de 177 discursos localizados no período analisado, incluindo Estados não-membros da ZOPACAS.

Como o Gráfico 2 demonstra, no ano de 1986, o primeiro analisado, nota-se um número muito superior ao de qualquer outro ano. Isso se justifica por ser o momento da criação da ZOPACAS, o que reforçou a presença do Atlântico Sul na pauta internacional. Ao longo dos quatro anos seguintes (1987-1990) o tema se manteve presente com uma intensidade relativamente alta, apresentando uma média de 14,5 menções ao ano. Entre os anos de 1991 e 1998 o número de menções sofreu uma queda considerável em relação ao período anterior, apresentando uma média de aproximadamente 7,6 menções ao ano. A partir do ano de 1999 constata-se uma queda vertiginosa no número de menções ao Atlântico Sul na AGNU, apresentando uma média de aproximadamente 1,76 menção ao tema por ano. 
GRÁFICO 2: EVOLUÇÃO ANUAL DO VOLUME TOTAL DE DISCURSOS LOCALIZADOS JUNTO À ONU ENTRE OS ANOS DE 1986 E 2015.

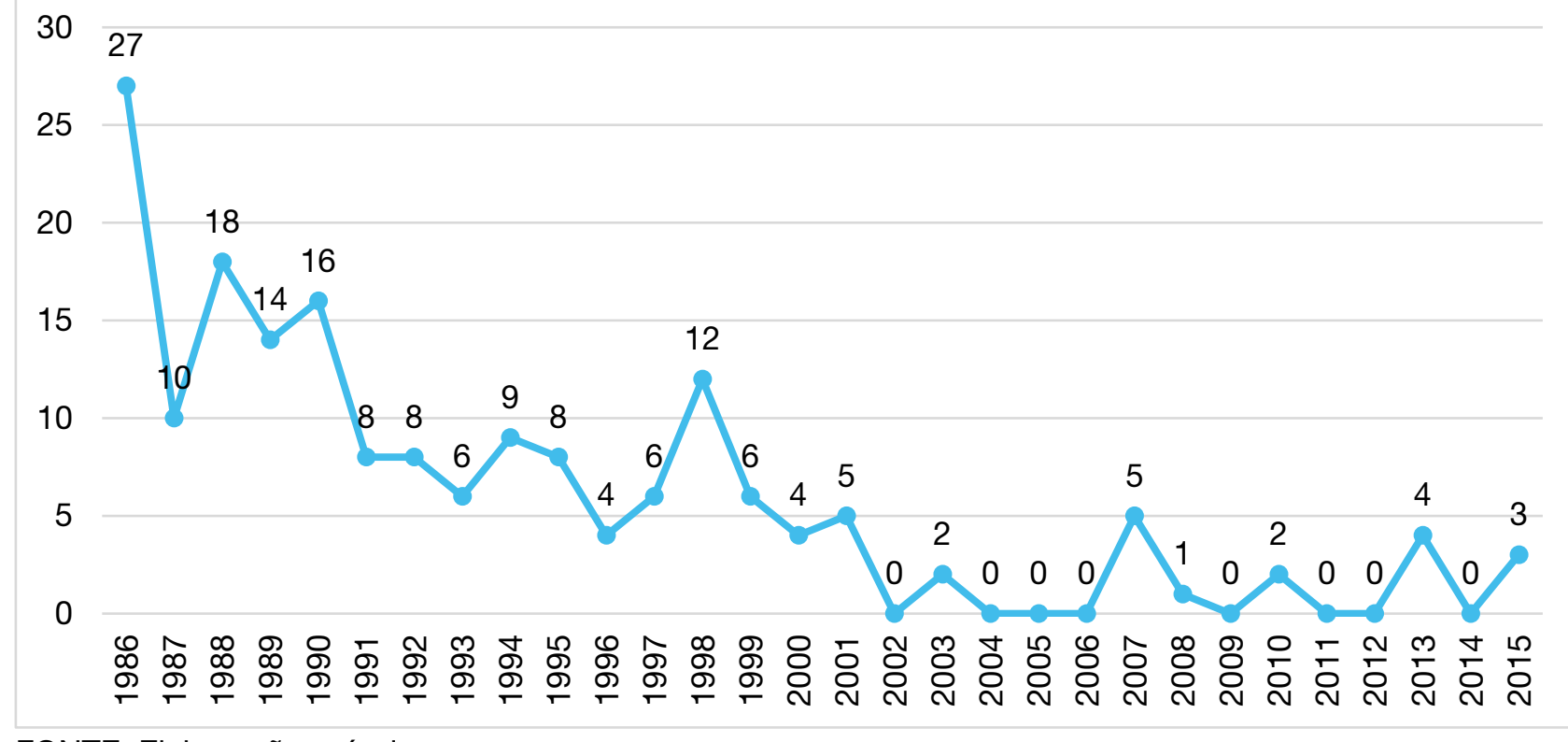

FONTE: Elaboração própria.

De forma complementar, o Gráfico 3 apresenta a evolução anual dos discursos concernentes ao Atlântico Sul junto à ONU proferidos exclusivamente pelos Estados-membros da ZOPACAS, apontando, em conjunto, as sete Reuniões Ministeriais da ZOPACAS realizadas no período recortado.

GRÁFICO 3: EVOLUÇÃO DO VOLUME TOTAL DE DISCURSOS DOS ESTADOS-MEMBROS DA ZOPACAS JUNTO À ONU EM FACE DAS REUNIÕES MINISTERIAIS DA ZOPACAS.

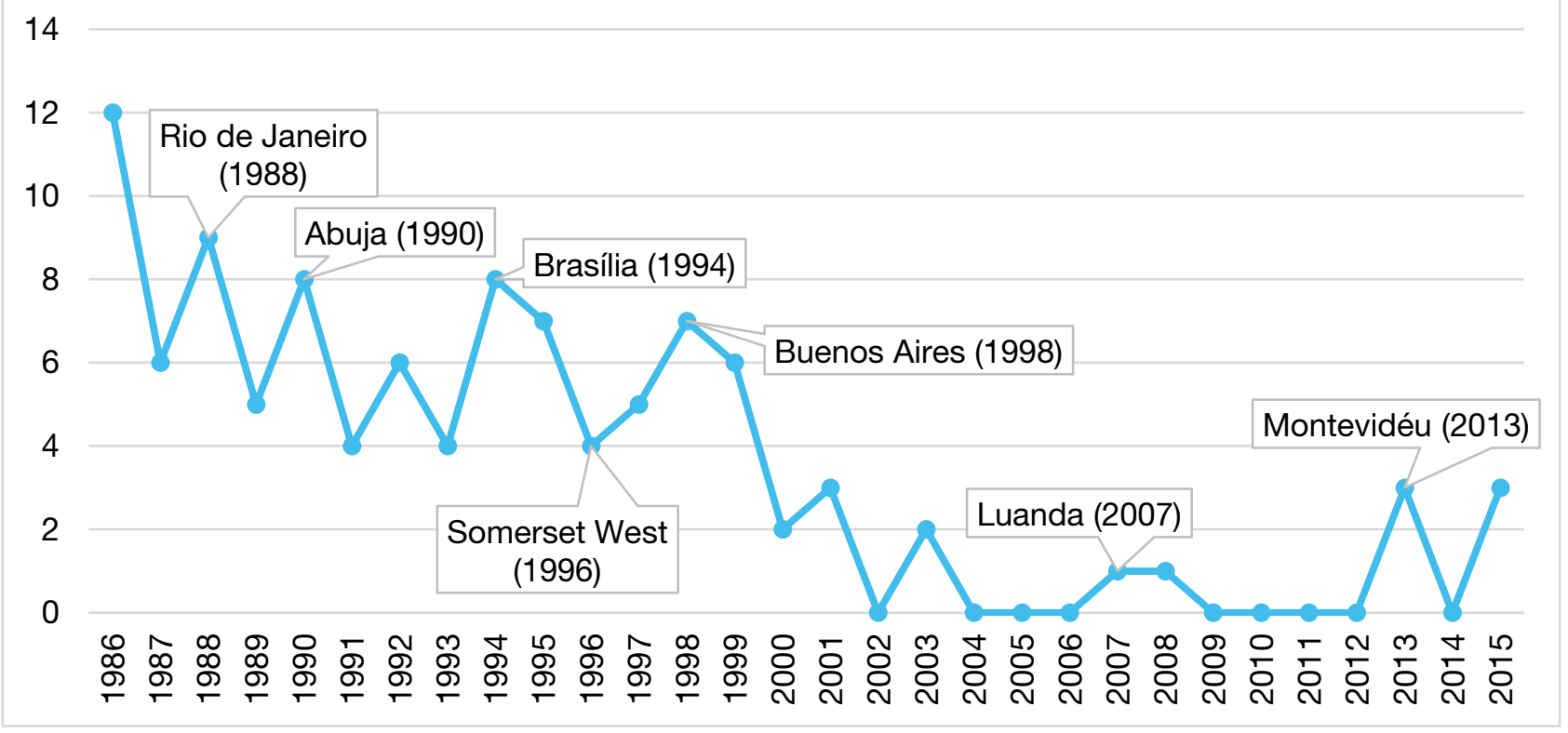

FONTE: Elaboração própria. 
Comparados os Gráficos 2 e 3, o primeiro fator que desperta a atenção é a maior linearidade dos dados ao se considerar apenas os discursos proferidos pelos membros da ZOPACAS. Enquanto os dados apresentados no Gráfico 2 apresentam um desvio padrão de aproximadamente 6,43 , os dados do Gráfico 3 possuem um desvio padrão de apenas 3,32. Isso indica que a atenção dos Estados não-membros da ZOPACAS sobre o território sul-atlântico se manifestou em seus discursos na ONU de modo desigual ao longo dos anos, sendo particularmente forte entre os anos de 1986 e 1991 (últimos anos da Guerra Fria), nos quais suas manifestações representaram 52,69\% do total registrado na ONU. Já no período entre 1992 e 2015, as manifestações dos Estados não-membros da ZOPACAS representaram apenas 25,3\% do total registrado.

De modo geral, é ainda perceptível que as Reuniões Ministeriais da ZOPACAS estão correlacionadas à elevação no volume total de discursos sobre o Atlântico Sul na AGNU nos respectivos anos em que as Reuniões Ministeriais ocorreram. Das setes reuniões, apenas a de Somerset West, ocorrida em 1996, marcou uma redução do volume total de discursos em relação ao ano anterior. Das reuniões do Rio de Janeiro (1988) à de Buenos Aires (1998), os anos com Reuniões Ministeriais da ZOPACAS representaram um aumento médio de aproximadamente $41,43 \%$ no volume total de discursos na AGNU em relação aos anos anteriores.

As reuniões de Luanda (2007) e Montevidéu (2013) representam um caso à parte, pois, apesar de ainda marcarem um período caracterizado pelo aumento no volume de discursos sobre o Atlântico Sul junto à ONU no ano em que ocorreram, esses números são distintamente reduzidos se comparados ao volume até 1998. Isso sugere a existência de três períodos no recorte temporal da pesquisa: (1) entre o surgimento da ZOPACAS (1986) e a Reunião Ministerial de Buenos Aires (1998), no qual a natureza e as dinâmicas do Atlântico Sul foram alvo de grande debate na AGNU e nas Reuniões Ministeriais da ZOPACAS; (2) entre as Reuniões de Buenos Aires (1998) e Luanda (2007), no qual os debates sobre o Atlântico Sul foram vagarosos e sem relevância; e (3) após a Reunião de Luanda (2007) que, apesar de marcar o reavivamento da ZOPACAS, não refletiu de modo significativo nos discursos sobre o Atlântico Sul na AGNU.

Adicionalmente, também é relevante observar as variações de frequência nas manifestações de cada Estado. Considera-se que identificar essas tendências é o primeiro passo para entender a forma como as percepções manifestas acerca do Atlântico Sul evoluíram ao longo dos anos. Nesse sentido, o Gráfico 4 apresenta o total de manifestações por ano dos sete Estados (Brasil, Nigéria, Argentina, Uruguai, África do Sul, Angola e Benim) que se manifestaram cinco ou mais vezes, sendo, portanto, os mais ativos nos debates sobre o tema na ONU. 
GRÁFICO 4: EVOLUÇÃO ANUAL DAS MENÇÕES AO ATLÂNTICO SUL NOS DISCURSOS NA ONU DE BRASIL, NIGÉRIA, ARGENTINA, URUGUAI, ÁFRICA DO SUL, ANGOLA E BENIM.

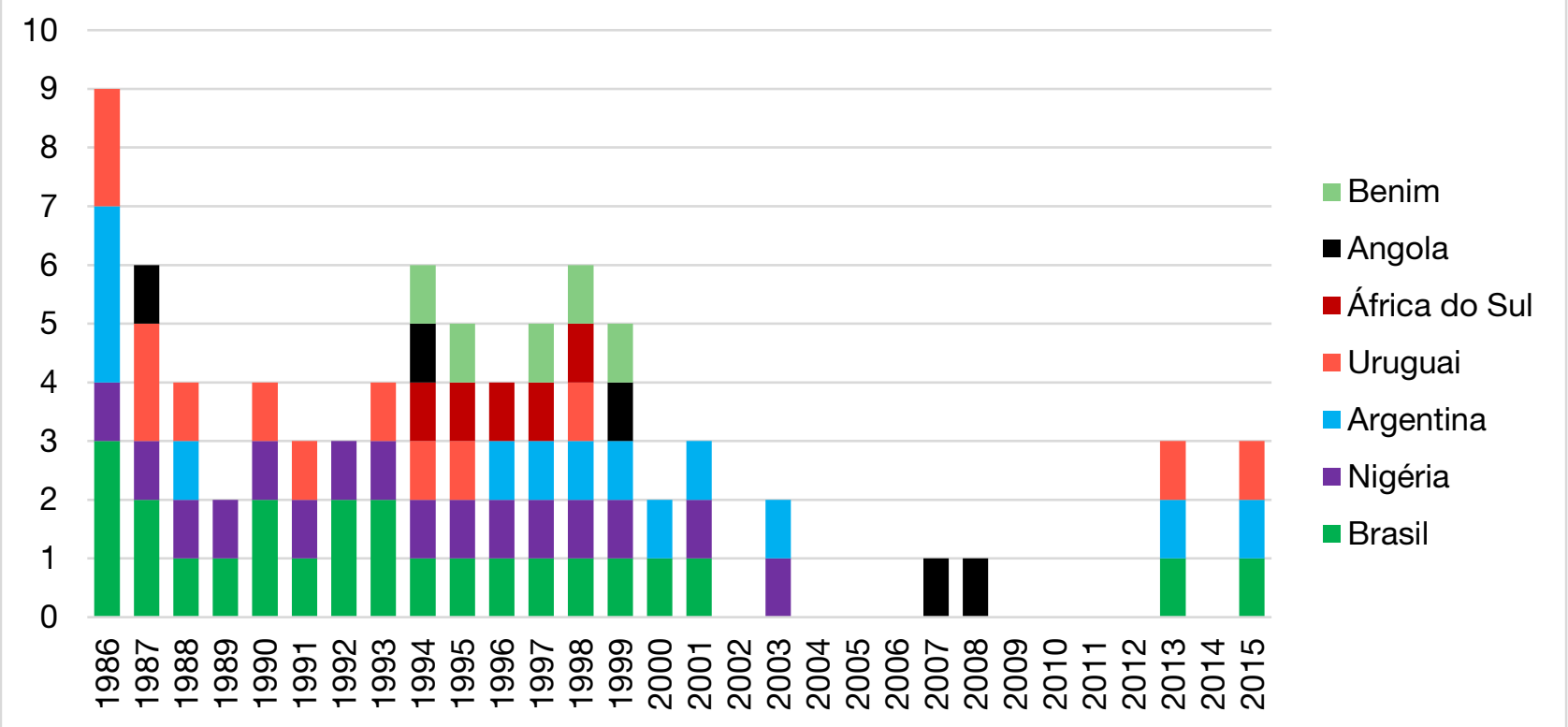

FONTE: Elaboração própria.

Algumas tendências podem ser notadas ao analisar o Gráfico 4. Em primeiro lugar, notase que Brasil e Nigéria foram os Estados que mais participaram dos debates e cuja participação se deu de modo mais constante. Por sua vez, embora a Argentina tenha demonstrado uma elevada participação nos debates, teve um amplo período de inatividade entre 1989 e 1995, retornando sua participação a partir de 1996. África do Sul e Benim apresentam dados curiosos, concentrando todas as suas participações entre 1994 e 1999. Já Angola demonstrou uma participação pouco ativa e muito espaçada nos debates até 1999, sendo, porém, o único Estado a se manifestar sobre o Atlântico Sul na ONU entre os anos de 2004 e 2012.

Concluída a análise geral dos dados que compõem a presente parcela do corpus da pesquisa, serão apresentados agora os dados obtidos a partir da análise de conteúdo dos discursos proferidos pelos Estados-membros da ZOPACAS na ONU, organizado de acordo com a dimensão de análise pré-estabelecida na qual as informações se inserem.

\subsection{DELIMITAÇÃO GEOGRÁFICA}

Dos 106 discursos considerados nessa parcela do corpus, em 92 destes foram identificadas menções em relação à delimitação geográfica do Atlântico Sul enquanto uma região. Três categorias foram derivadas dos textos analisados dentro desta dimensão de análise, a qual diz respeito aos limites territoriais indicados em cada discurso como sendo a dimensão física da região. São elas: 
(1) Atlântico Sul identificado como espaço de interação entre África e América do Sul, interpretação que considera a área oceânica não como uma região propriamente dita, mas apenas um espaço territorial entre as regiões africana e sul-americana, identificada pelo rótulo $\mathrm{A} 1$;

(2) Atlântico Sul como espaço regional que une América do Sul e África sem ser diretamente associado à ZOPACAS, postura que o considera como uma região propriamente dita, mas não estabelece recortes claros para os seus limites geográficos, identificada pelo rótulo A2;

(3) E Atlântico Sul como espaço regional diretamente associado à ZOPACAS, postura que o considera como uma região propriamente dita e cujos limites geográficos são diretamente associados à ZOPACAS, identificada pelo rótulo A3.

Nesses termos, os dados acerca da delimitação geográfica do Atlântico Sul, conforme manifestos nos discursos proferidos pelos membros da ZOPACAS na ONU, podem ser reunidos em dois grandes grupos: o primeiro se resume à primeira categoria, considerando o oceano como um mero espaço de interação entre duas regiões (América do Sul e África Ocidental), enquanto o segundo reúne as demais categorias e considera o Atlântico Sul como uma região com identidade própria. O Gráfico 5 expõe a evolução anual do volume total de discursos que apontaram o Atlântico Sul como um espaço de interação entre duas regiões ou uma região com identidade própria. Por sua vez, o Gráfico 6 expõe a divisão anual entre os discursos que consideram os limites geográficos do Atlântico Sul como alheios ou diretamente associados à ZOPACAS.

GRÁFICO 5: EVOLUÇÃO ANUAL DAS PERCEPÇÕES MANIFESTAS EM RELAÇÃO AO CARÁTER REGIONAL DO ATLÂNTICO SUL

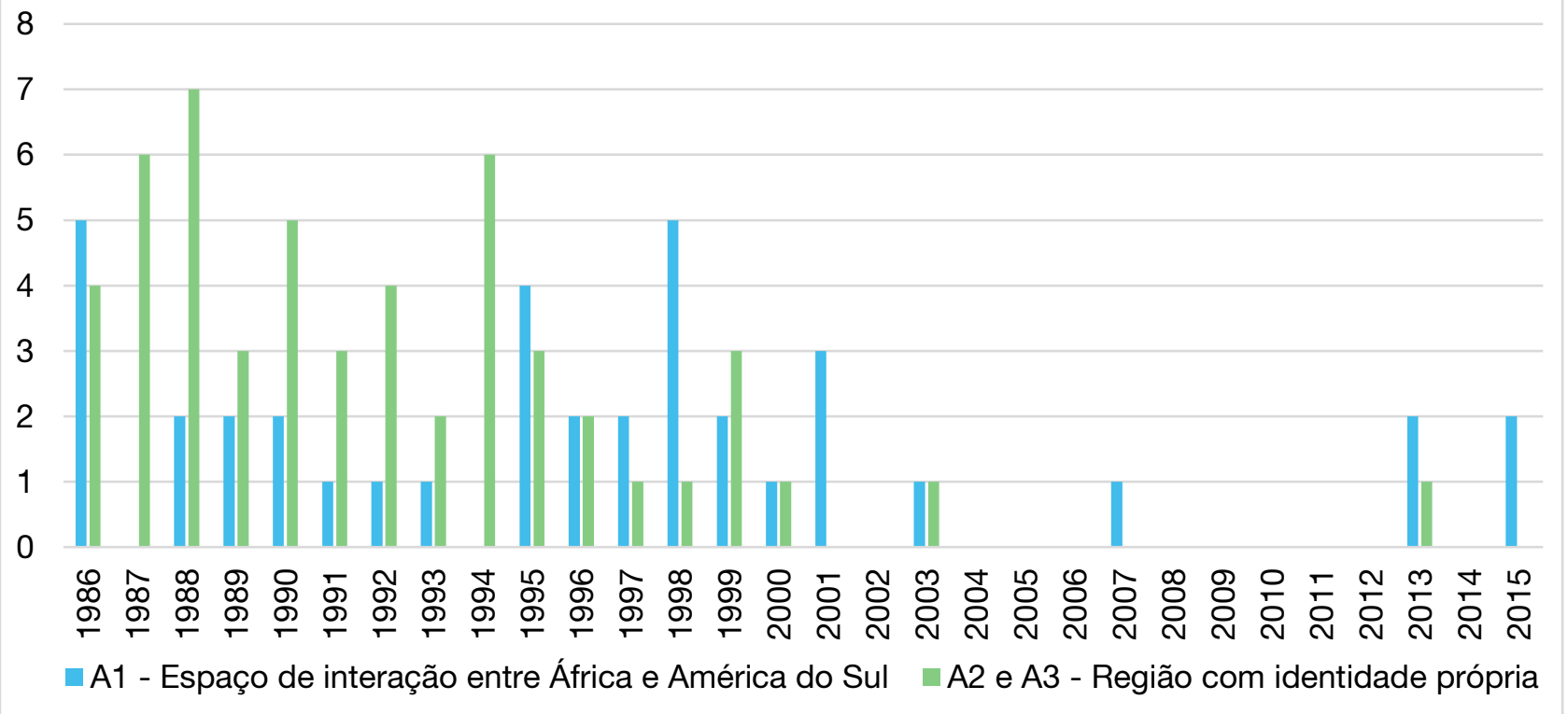

FONTE: Elaboração própria. 
GRÁFICO 6: EVOLUÇÃO ANUAL DAS PERCEPÇÕES MANIFESTAS EM RELAÇÃO AO CARÁTER REGIONAL DO ATLÂNTICO SUL COMO ALHEIO OU DIRETAMENTE ASSOCIADO À ZOPACAS

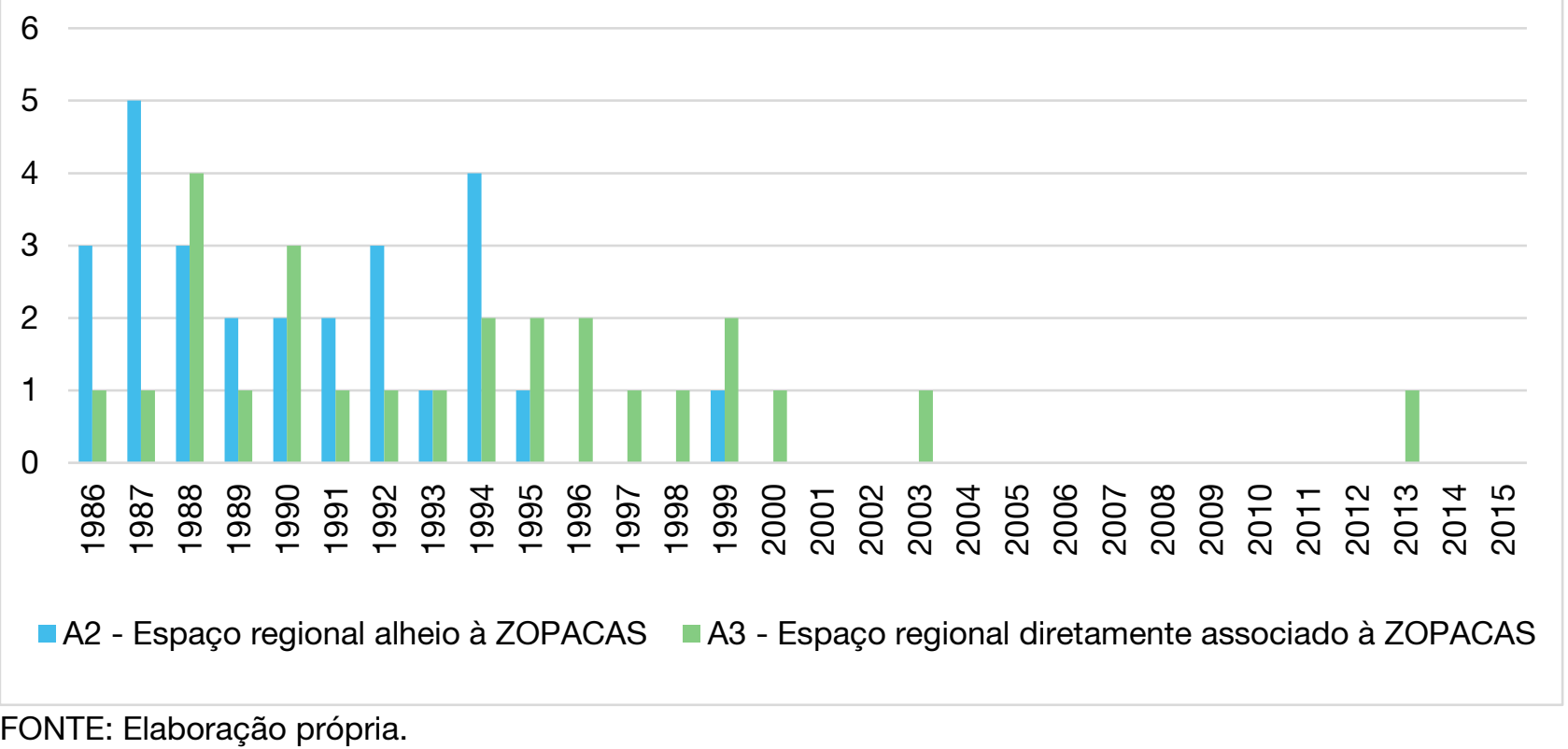

Ao todo, dos 92 discursos que apresentaram menções em relação à delimitação geográfica do Atlântico Sul enquanto uma região, 39 deles $(42,39 \%)$ o considera como um mero espaço de interação entre América do Sul e África. Dos demais, 27 (29,35\%) discursos apontam para a percepção do Atlântico Sul como uma região cujo espaço é alheio a ZOPACAS (sem definir os seus limites), enquanto 26 (28,26\%) associam o espaço regional diretamente à ZOPACAS.

Ainda tratando das manifestações sobre a delimitação geográfica do Atlântico Sul, o Gráfico 7 expõe o volume total de discursos de acordo com o Estado que os manifestou.

GRÁFICO 7: VOLUME TOTAL DE DISCURSOS QUE MANIFESTAM PERCEPÇÕES EM RELAÇÃO AO CARÁTER REGIONAL DO ATLÂNTICO SUL DE ACORDO COM CADA ESTADO

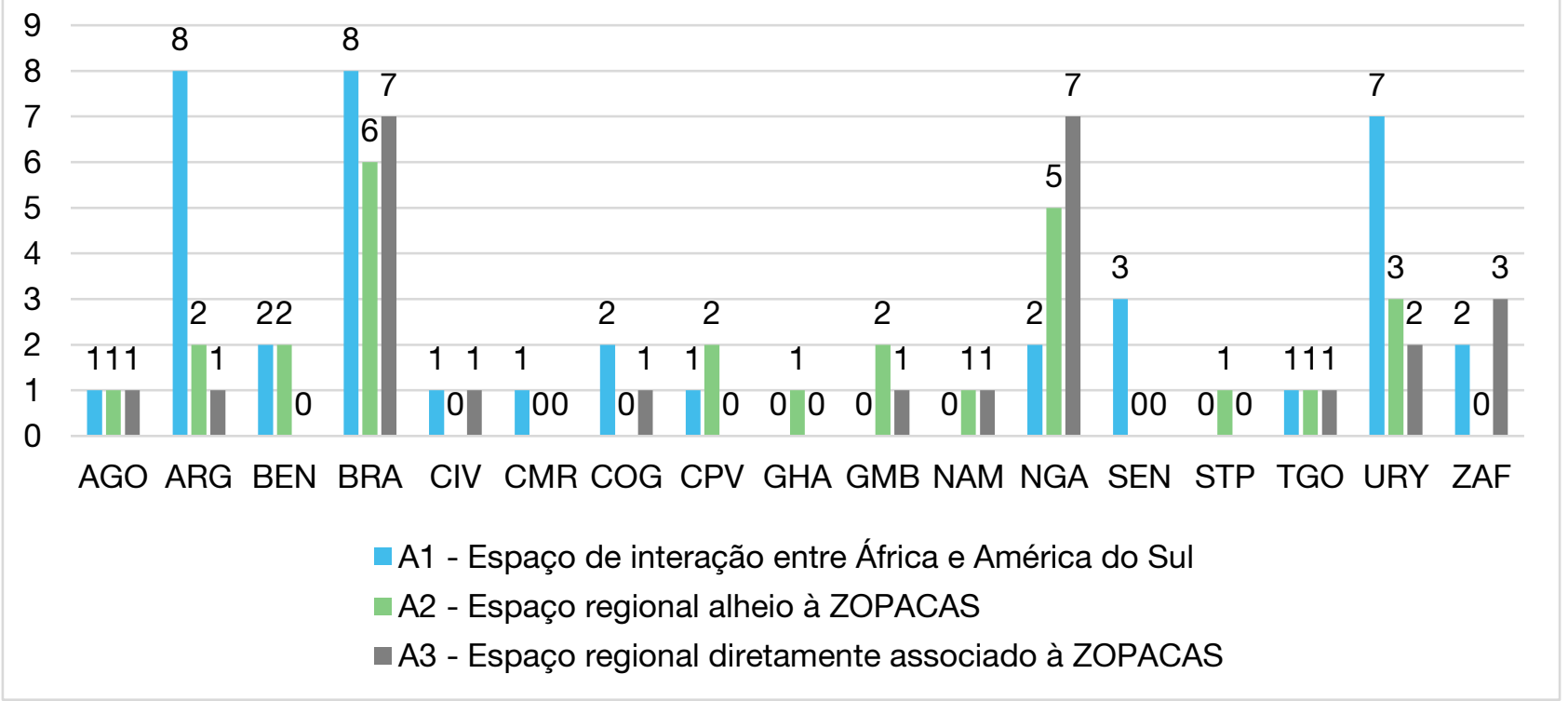

FONTE: Elaboração própria. 
Dos 24 Estados-membros da ZOPACAS, foram registradas manifestações relevantes em relação à delimitação geográfica da ZOPACAS nas falas de 17 deles. Destes, apenas Brasil (21 manifestações), Nigéria (14 manifestações), Uruguai (12 manifestações) e Argentina (11 manifestações) registraram um volume de manifestações relevantes na presente dimensão de análise superior a 10, seguidos, então, por África do Sul (5 manifestações) e Benin (4 manifestações). Nos casos de Uruguai e Argentina, os dados apontam de forma expressiva para a crença manifesta de que o Atlântico Sul não é uma região com características próprias, sendo seu território apenas um espaço de interação entre a América do Sul e a África Ocidental. Nos casos de Brasil e Nigéria, a percepção do Atlântico Sul como um espaço entre regiões ainda é presente (sobretudo no caso brasileiro, representando 38,09\% das manifestações totais do Estado), mas as manifestações no sentido de o Atlântico Sul ser uma região com identidade própria se sobressaem como maioria.

\subsection{RELAÇÕES POLÍTICAS}

No que toca às relações políticas internacionais ou transnacionais, expressas pelos Estados como próprias ao Atlântico Sul, foram localizadas seis categorias ao longo dos 106 discursos analisados. Seu fator comum é a forma como são apresentadas como sendo questões inerentes à existência e gestão do próprio espaço regional. São elas:

(1) Manutenção do Atlântico Sul como Zona não nuclear, fazendo referência aos discursos que focam especificamente na necessidade de preservar o território sul-atlântico como um ambiente livre de armas nucleares, sendo este o argumento precursor da ZOPACAS, identificada pelo rótulo $\mathrm{B} 1$;

(2) Cooperação socioeconômica para o desenvolvimento, que descreve as relações políticas entre os Estados do Atlântico Sul como amistosas, exaltando a ideia de cooperação SulSul para o desenvolvimento econômico e social, identificada pelo rótulo B2;

(3) Combate às "novas ameaças" da segurança internacional, com foco específico no combate ao crime organizado internacional, dando ênfase ao tráfico de drogas e armas de pequeno calibre, identificada pelo rótulo B3;

(4) Proteção do meio ambiente e dos recursos naturais, categoria que se refere a discursos favoráveis a uma postura cooperativa em uma ampla gama de problemáticas, como a ampliação dos acordos internacionais sobre lixo radioativo e combate à pesca ilegal, identificada pelo rótulo B4; 
(5) Questões de segurança e paz tratadas de modo geral, referindo-se a questões de segurança e paz não relacionadas à questão das armas nucleares, identificada pelo rótulo B5;

(6) E o combate a ingerências externas, referindo-se à percepção manifesta do risco de potências externas ao Atlântico Sul tentarem impor seu controle sobre o território, tanto diretamente, como percebido no caso das Ilhas Falklands, quanto indiretamente, influenciando as dinâmicas políticas locais, identificada pelo rótulo B6.

É importante notar que cada discurso pode ter apresentado mais de uma única categoria na presente dimensão de análise observada. Isso se deve pois, comumente, os representantes estatais se manifestaram apontando mais de um único campo como relevante nas dinâmicas políticas internacionais no espaço em questão ${ }^{7}$.

O Gráfico 8 apresenta a evolução anual das relações políticas no conjunto total de discursos analisados nessa parcela do corpus da pesquisa. Para fins de melhor visualização, os anos nos quais não foi localizado nenhum discurso foram excluídos da representação gráfica ${ }^{8}$.

GRÁFICO 8: EVOLUÇÃO ANUAL DAS PERCEPÇÕES MANIFESTAS EM RELAÇÃO ÀS RELAÇÕES POLÍTICAS INTERNACIONAIS OU TRANSNACIONAIS PRÓPRIAS AO ATLÂNTICO SUL

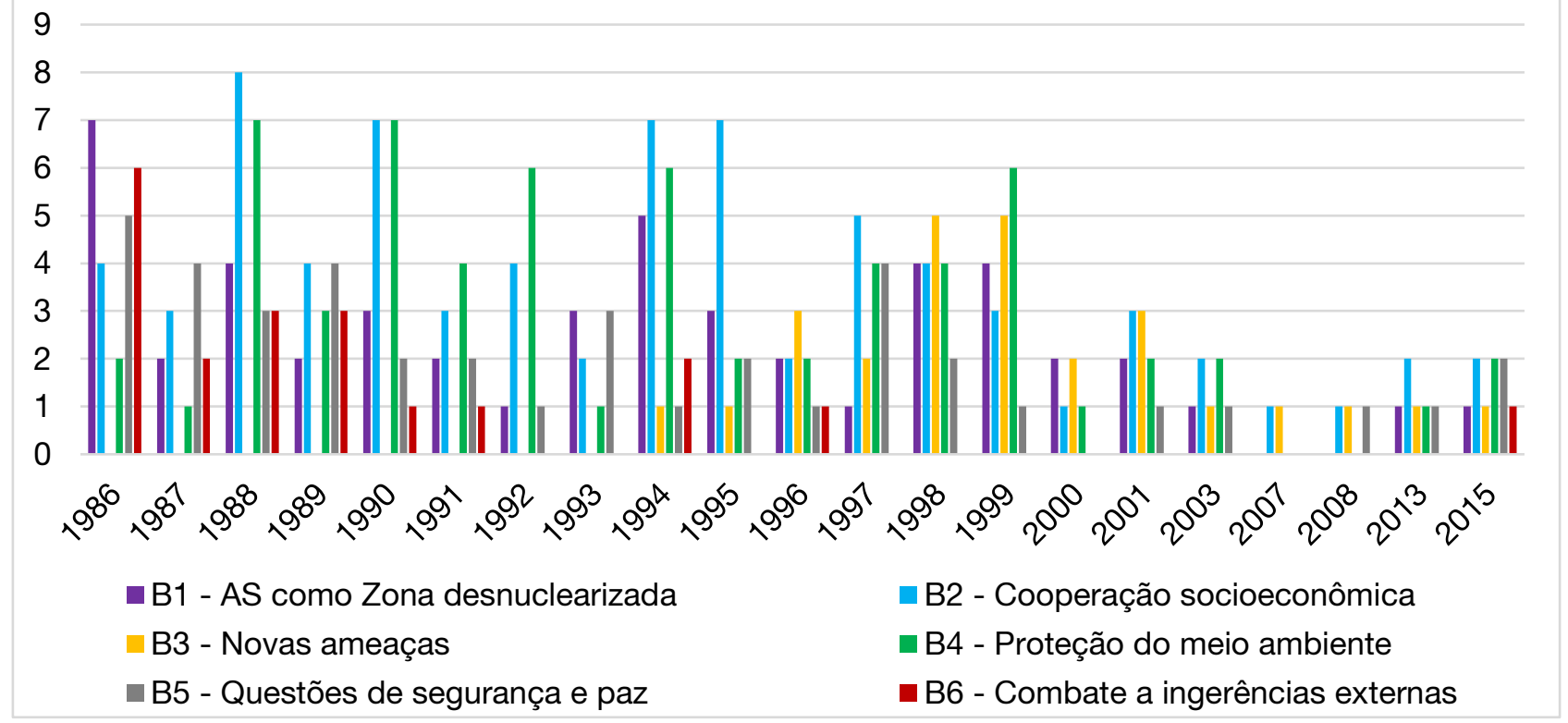

FONTE: Elaboração própria.

\footnotetext{
${ }^{7}$ A título de exemplo, durante a $49^{a}$ Reunião da AGNU, o representante brasileiro, ao tratar dos avanços promovidos na II Reunião Ministerial da ZOPACAS, ocorrida em 1990 em Abuja, declara: "Três áreas centrais de cooperação foram identificadas: meio ambiente marinho; desnuclearização; e cooperação empresarial" (Brasil, 1994, p.13, tradução nossa). Neste caso, o discurso em questão foi inserido nas categorias "proteção do meio ambiente e dos recursos naturais", "manutenção do Atlântico Sul como Zona não nuclear" e "cooperação socioeconômica para o desenvolvimento".

${ }^{8}$ São eles: 2002, 2004, 2005, 2006, 2009, 2010, 2011, 2012 e 2014.
} 
A análise do Gráfico 8 revela a primazia das dinâmicas de cooperação socioeconômica e das dinâmicas de proteção cooperativa do meio ambiente e dos recursos naturais ao longo do período analisado. No caso da cooperação socioeconômica, nota-se a presença deste elemento em aproximadamente $84,78 \%$ dos discursos analisados (78 citações), se mostrando presente de modo constante ao longo de todo o recorte temporal da pesquisa. Já as dinâmicas relacionadas à proteção do meio ambiente e dos recursos naturais se mostraram presentes em $70,65 \%$ dos discursos analisados (65 citações), com uma constância equiparável à categoria anteriormente citada, salvo os anos entre 2004 e 2012, nos quais os próprios debates sobre o Atlântico Sul na ONU foram quase inexistentes. Estes dados reforçam a ideia de que a relevância política do espaço sul-atlântico se constrói em grande parte baseado em sua importância econômica para os Estados por ele banhados, seja através dos projetos de cooperação para o desenvolvimento entre os Estados ou das riquezas naturais que o mesmo oferece.

Logo em seguida aparecem as dinâmicas de segurança, tendo os esforços para manter o Atlântico Sul como uma zona desnuclearizada presentes em, aproximadamente, 56,52\% dos discursos (51 citações), enquanto as demais dinâmicas de segurança e paz estiveram presentes em aproximadamente $46,74 \%$ dos discursos analisados (43 citações). No que se refere à questão do Atlântico Sul enquanto uma zona desnuclearizada, nota-se que as manifestações nesse sentido são particularmente presentes no início do período recortado, o que não é surpreendente se for considerado que este condiz com o período de surgimento da ZOPACAS, cujo argumento fundador era precisamente manter o Atlântico Sul livre de armas nucleares. Esse elemento se manteve forte até 1994, ano que marcou o fim do regime do Apartheid na África do Sul junto com seu programa nuclear, reduzindo a necessidade empírica da pauta. Em oposição, a categoria de "novas ameaças" só aparece pela primeira vez no ano de 1994, se tornando pauta relevante até o ano de 2001. Se for considerado que a partir do século XXI os debates sobre o Atlântico Sul na AGNU foram reduzidos como um todo (sendo, inclusive, inexistentes em vários anos), a pauta do tráfico de drogas e armas acaba se mostrando relevante até certo grau, mas apenas em um período bem específico entre os anos de 1996 até 2001, no qual a categoria esteve presente em aproximadamente $74,07 \%$ dos discursos proferidos (20 discursos de um total de 27 no referido período).

Estando estas pautas relacionadas em algum grau, é necessário ainda considerar os índices de coocorrência que estas categorias apresentaram entre si. A Tabela 2 apresenta a relação completa de coocorrências das categorias das relações políticas dentro de um mesmo discurso. 
TABELA 2: CO-OCORRÊNCIA EM UM MESMO DISCURSO DAS CATEGORIAS DE RELAÇÕES POLÍTICAS

\begin{tabular}{|c|c|c|c|c|c|c|}
\hline & B1 (52) & B2 (78) & B3 (30) & B4 (65) & B5 (43) & B6 (20) \\
\hline B1 (52) & & 30 & 15 & 31 & 12 & 11 \\
\hline B2 (78) & 30 & & 18 & 49 & 32 & 14 \\
\hline B3 (30) & 15 & 18 & & 18 & 7 & 1 \\
\hline B4 (65) & 31 & 49 & 18 & & 20 & 9 \\
\hline B5 (43) & 12 & 32 & 7 & 20 & & 10 \\
\hline B6 (20) & 11 & 14 & 1 & 9 & 10 & \\
\hline
\end{tabular}

FONTE: Elaboração própria.

No que toca às categorias de natureza econômica (cooperação e proteção ao meio ambiente e recursos naturais), as duas aparecem juntas em um total de 49 discursos, portanto, ao menos uma das pautas está presente em um total de 94 discursos (aproximadamente 88,67\% do total de 106 discursos analisados). Já no que toca às dinâmicas de segurança, estas apresentaram uma coocorrência em 12 discursos, o que aponta para um total de 83 discursos (aproximadamente $78,30 \%$ do total) apresentando alguma menção às dinâmicas de segurança.

\subsection{FATORES IDENTITÁRIOS}

A dimensão de análise dos fatores identitários relacionados ao espaço regional foi, como um todo, a que menos apresentou manifestações dentro de suas categorias de análise. Duas categorias foram derivadas dos discursos analisados, sendo elas:

(1) Conexões históricas e culturais, nas quais os atores realçam elementos históricos do Atlântico Sul e dos povos cujas terras são por ele banhados, usualmente relacionados ao colonialismo e ao tráfico de escravos de séculos passados, identificada pelo rótulo C1;

(2) E desafios e potencialidades em comum, perspectiva na qual se trabalha com a ideia de que os Estados do Atlântico Sul estão unidos por problemas comuns e devem buscar soluções de modo cooperativo, identificada pelo rótulo C2.

O Gráfico 9 apresenta a evolução anual do volume de discursos com trechos que expressaram a percepção de fatores identitários que ligam as duas costas do Atlântico Sul. 
GRÁFICO 9: EVOLUÇÃO ANUAL DAS PERCEPÇÕES MANIFESTAS EM RELAÇÃO AOS FATORES IDENTIRÁRIOS EXISTENTES ENTRE OS ESTADOS DO ATLÂNTICO SUL

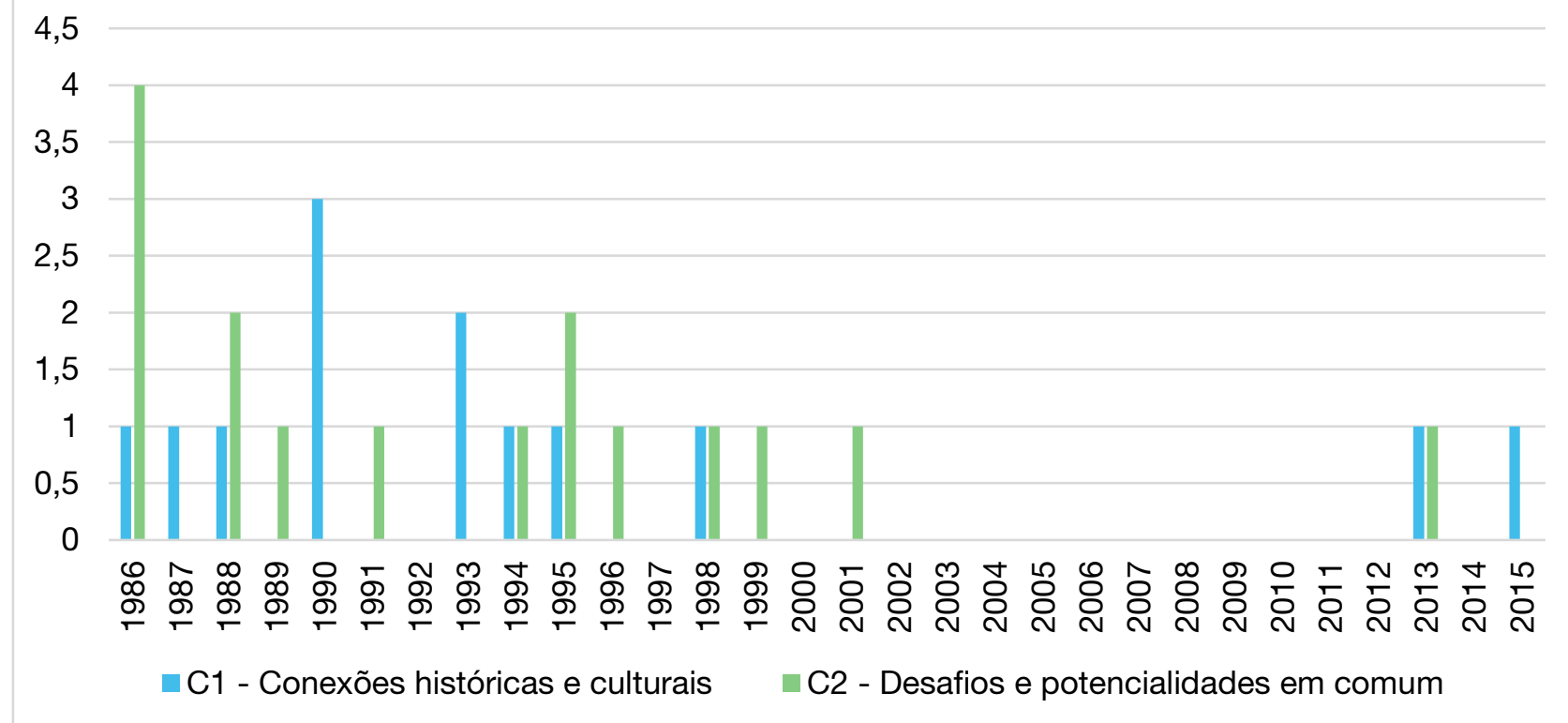

FONTE: Elaboração própria

Comparado aos Gráficos 5 e 8, os quais expressam, respectivamente, a evolução anual das categorias relacionadas à dimensão geográfica e às relações políticas regionais, o Gráfico 9 evidencia de modo claro o volume reduzido de manifestações em relação aos fatores identitários em oposição às dimensões previamente analisadas. Ao todo, houve apenas 29 menções a fatores identitários ao longo dos discursos analisados (englobando suas duas categorias), ao passo que foram registradas 92 menções na dimensão de análise do espaço geográfico e 276 menções a relações políticas regionais.

Se comparados às dimensões que serão analisadas em sequência, esses dados são igualmente baixos: na dimensão de análise de menção a outros Estados (dimensão D) foram registradas 91 citações, enquanto em relação a outras dinâmicas políticas (dimensão E) foram observados 128 registros. Isto posto, apesar de seu baixo volume de dados coletados, as categorias de fatores identitários não devem ser ignoradas, dado que estas se relacionam diretamente a forma como o território em questão é pensado e potencialmente construído enquanto uma região.

Por sua vez, o Gráfico 10 expõe quais Estados foram responsáveis pelas manifestações observadas dentro destas duas categorias. 
GRÁFICO 10: VOLUME TOTAL DE MANIFESTAÇÕES SOBRE OS FATORES IDENTITÁRIOS EXISTENTES ENTRE OS ESTADOS DO ATLÂNTICO SUL DE ACORDO COM OS ESTADOS QUE ÀS MANIFESTARAM

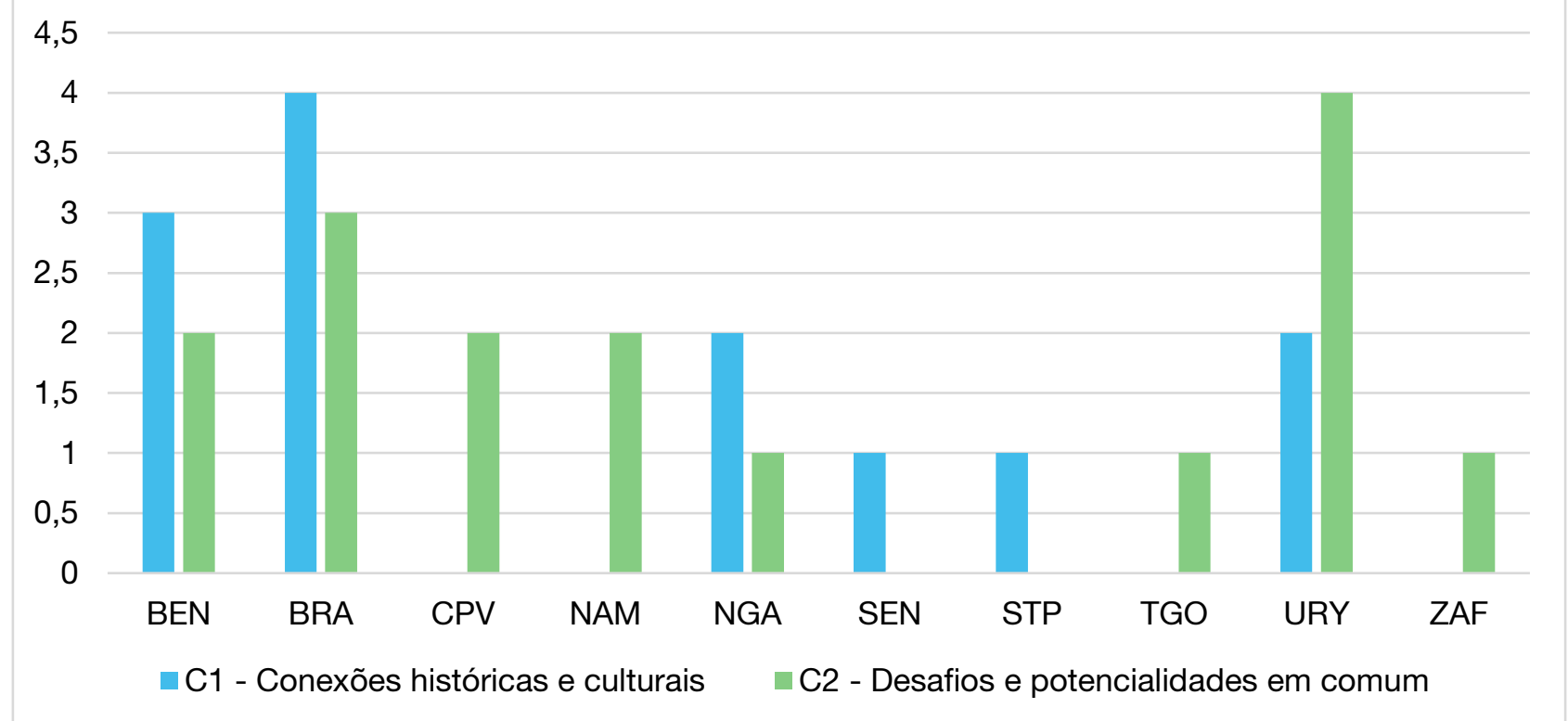

FONTE: Elaboração própria.

Observando exclusivamente o Gráfico 10, nota-se que os representantes do Benin, Brasil e Uruguai foram aqueles que mais abordaram fatores identitários em seus discursos. As duas categorias de manifestações parecem ter um grau de relevância muito parecido, tendo sido observados 13 discursos citando conexões históricas e 16 citando os desafios e potencialidades em comum. Curiosamente, a categoria de desafios e potencialidades em comum teve discursos enquadrados já em 1986, tendo naquele ano registrado ao menos o dobro de citações se comparada a qualquer outro ano analisado. Isso sugere de modo incisivo que a ideia dos Estados da América do Sul e da África Ocidental compartilharem desafios e potencialidades em comum é um fator identitário antigo na relação destes Estados (sobretudo nas dinâmicas relacionadas ao Atlântico Sul) e não um elemento que foi posteriormente introduzido pela política externa brasileira nos anos 2000.

\subsection{Citação A Outros Atores}

Como descrito anteriormente, essa dimensão de análise busca mapear quais são os atores vistos como lideranças regionais, o que fortalece as inferências sobre os atores que atuam como region-builders. No caso da presente pesquisa, isso foi feito através da identificação de quais destes atores são citados nos discursos dos demais com um teor que reconhece suas contribuições na construção de um espaço sul-atlântico colaborativo e integrado.

Ao todo, os seguintes Estados foram citados ao menos uma vez nos discursos de seus pares: 
(1) Brasil, identificado pelo rótulo D1;

(2) Argentina, identificada pelo rótulo D2;

(3) África do Sul, identificada pelo rótulo D3;

(4) Nigéria, identificada pelo rótulo D4;

(5) Benin, identificado pelo rótulo D5;

(6) Uruguai, identificado pelo rótulo D6;

(7) Namíbia, identificada pelo rótulo D7;

(8) Angola, identificada pelo rótulo D8;

(9) Cabo Verde, identificado pelo rótulo D9;

(10) Gana, identificada pelo rótulo D10;

(11) E Gabão, identificado pelo rótulo D11.

O Gráfico 11 apresenta a evolução temporal de quantas vezes cada Estado foi citado por seus pares em determinado ano. Vale ainda notar que cada discurso pode ter apresentado mais de uma única categoria na presente dimensão de análise observada, sendo usual a menção de dois ou mais Estados em um mesmo discurso. Ressalta-se ainda que, para fins de melhor visualização gráfica, os Estados que tiveram um volume total de citações inferior a cinco foram agrupados no rótulo "outros"?.

\section{GRÁFICO 11: EVOLUÇÃO ANUAL DE CITAÇÕES DE CADA ESTADO POR SEUS PARES}

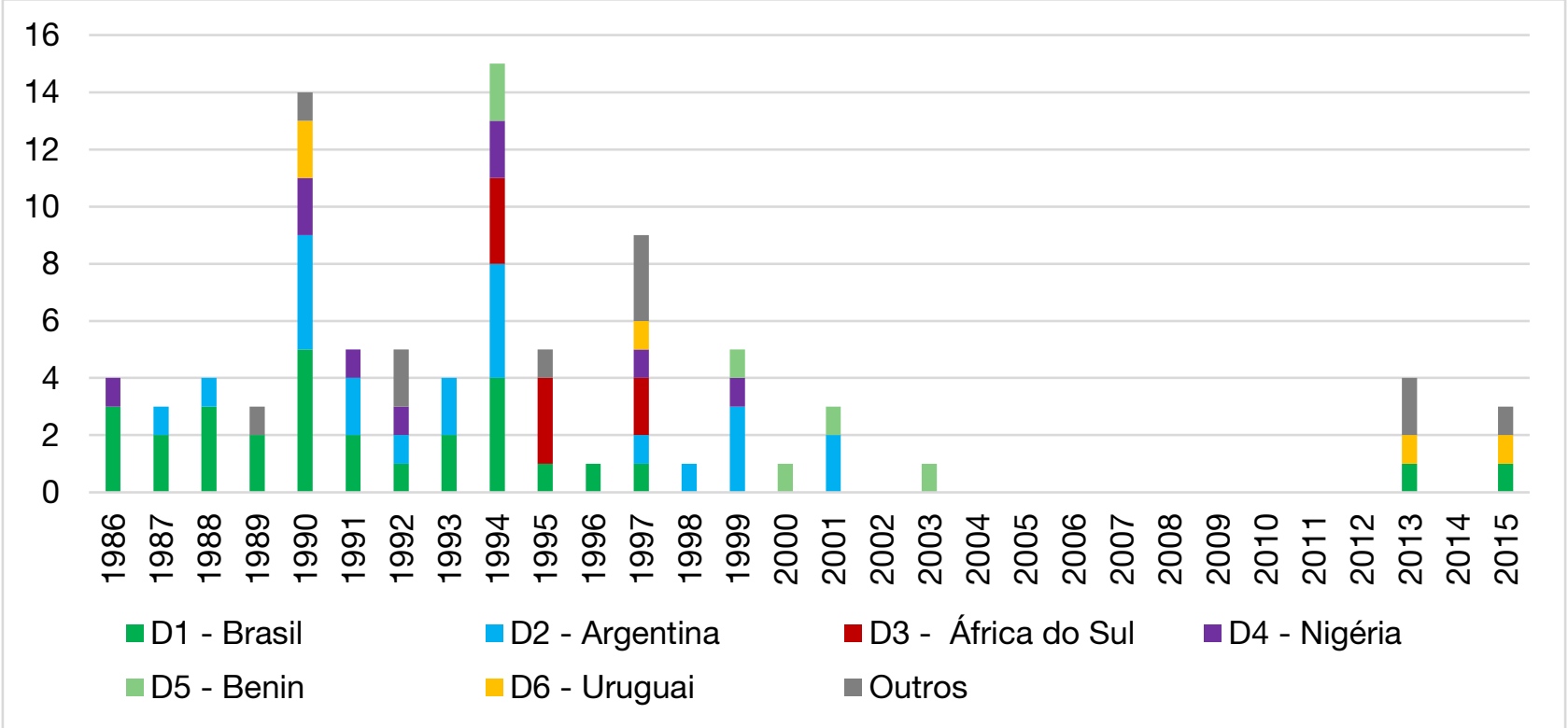

FONTE: Elaboração própria.

\footnotetext{
${ }^{9}$ São eles: Namíbia, com quatro citações; Angola, com três citações; Cabo verde, com duas citações; Gana e Gabão, com uma citação cada.
} 
Os dados revelam um protagonismo intenso e constante por parte de Brasil e Argentina, os quais tiveram, respectivamente, 29 e 22 citações por outros Estados ao longo do período analisado. Embora comparativamente tenha sido citado um número inferior de vezes, também é notável o papel reconhecido da Nigéria, com nove menções entre 1986 e 1999. No caso da África do Sul, com oito citações, estas estão concentradas no período de 1994 a 1997, período que se inicia ao fim do regime do Apartheid sul-africano e subsequente reintrodução da África do Sul na sociedade internacional. Como já demonstrado no Gráfico 4, esse período coincide com os anos que concentraram todos os pronunciamentos da África do Sul sobre o Atlântico Sul na AGNU, sendo, também, o ano de 1994 aquele no qual o país se tornou membro da ZOPACAS. Os dados sugerem que nesse curto período a África do Sul exerceu protagonismo nas dinâmicas em questão.

Adicionalmente, o Gráfico 12 apresenta os Estados responsáveis pelas menções de Brasil, Argentina, África do Sul e Nigéria, os mais citados por seus pares nos discursos sobre o Atlântico Sul. De modo geral, as citações aos quatro Estados em questão se deram de modo disperso, com os quatro apresentando um grau elevado de citações uns aos outros. Destes, Brasil e Argentina são particularmente relevantes, o que não surpreende uma vez considerado o fato de que foram os Estados mais citados de modo geral.

GRÁFICO 12: RELAÇÃO DOS ESTADOS RESPONSÁVEIS PELAS CITAÇÕES AO BRASIL, ARGENTINA, ÁFRICA DO SUL E NIGÉRIA NA AGNU

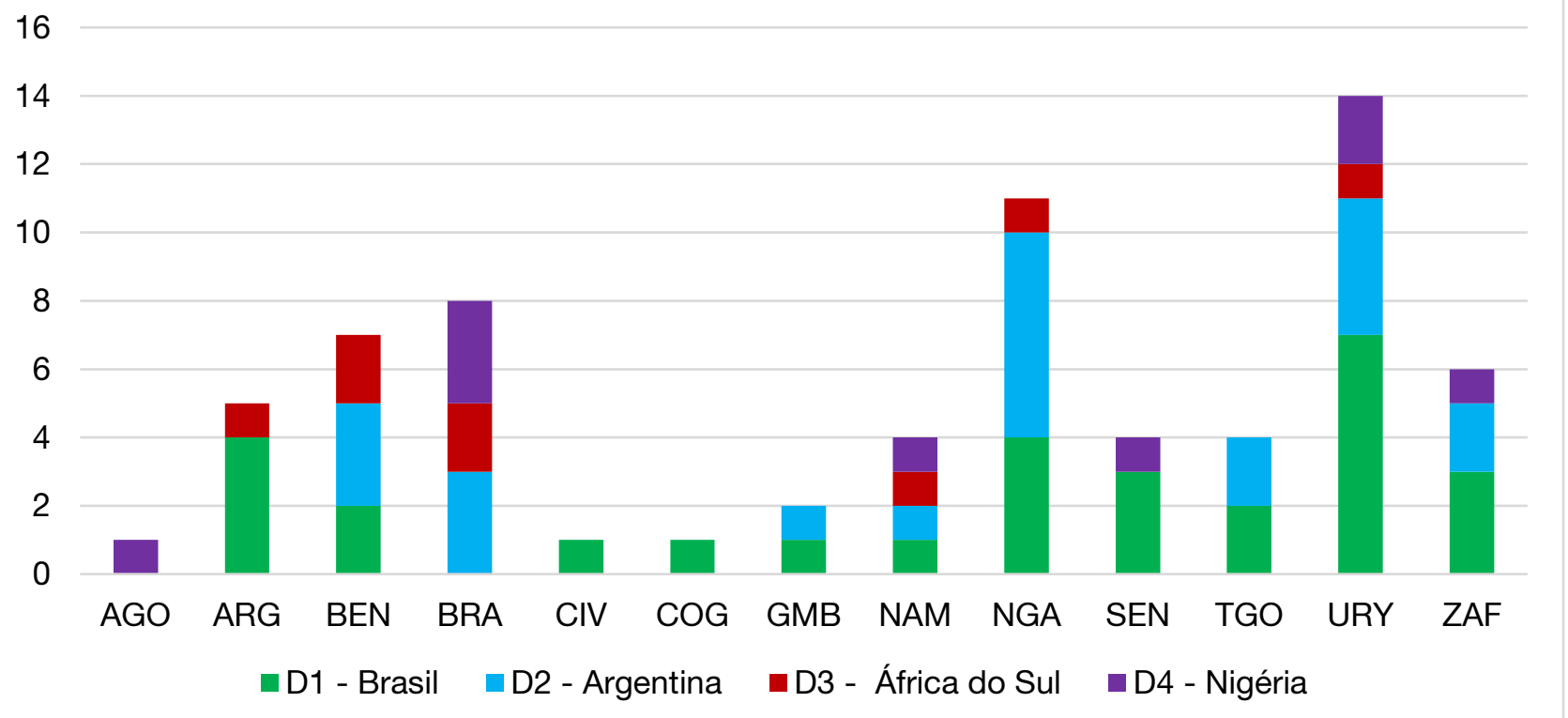

FONTE: Elaboração própria.

Em relação aos demais Estados, aquele que mais se manifestou foi o Uruguai, citando o Brasil ou Argentina em aproximadamente 53,84\% de seus discursos. Esse número já considera a coocorrência de citações aos dois Estados, a qual, no caso das manifestações uruguaias, se deu em todas as menções a Argentina (isto é, todas as vezes que a Argentina foi citada, o Brasil também 
foi). Nesse sentido, a Tabela 3 expõe as coocorrências de citações a mais de um Estado em um mesmo discurso.

TABELA 3: CO-OCORRÊNCIA EM UM MESMO DISCURSO DAS CITAÇÕES A OUTROS ESTADOS

\begin{tabular}{|c|c|c|c|c|c|c|c|c|c|c|c|}
\hline & D1 & D2 & D3 & D4 & D5 & D6 & D7 & D8 & D9 & D10 & D11 \\
\hline D1 & & 14 & 3 & 5 & 1 & 3 & 2 & 1 & 1 & 1 & 0 \\
\hline D2 & 14 & & 3 & 4 & 2 & 3 & 2 & 1 & 0 & 1 & 0 \\
\hline D3 & 3 & 3 & & 1 & 2 & 0 & 0 & 1 & 0 & 0 & 1 \\
\hline D4 & 5 & 4 & 1 & & 1 & 1 & 1 & 1 & 0 & 0 & 0 \\
\hline D5 & 1 & 2 & 2 & 1 & & 0 & 0 & 0 & 0 & 0 & 0 \\
\hline D6 & 3 & 3 & 0 & 1 & 0 & & 1 & 1 & 1 & 0 & 0 \\
\hline D7 & 2 & 2 & 0 & 1 & 0 & 1 & & 1 & 0 & 0 & 0 \\
\hline D8 & 1 & 1 & 1 & 1 & 0 & 1 & 1 & & 1 & 0 & 0 \\
\hline D9 & 1 & 0 & 0 & 0 & 0 & 1 & 0 & 1 & & 0 & 0 \\
\hline D10 & 1 & 1 & 0 & 0 & 0 & 0 & 0 & 0 & 0 & & 0 \\
\hline D11 & 0 & 0 & 1 & 0 & 0 & 0 & 0 & 0 & 0 & 0 & \\
\hline
\end{tabular}

FONTE: Elaboração própria.

A análise da Tabela 3 revela apenas a incidência de um índice de coocorrência de citações elevado entre Brasil e Argentina, os quais foram citados juntos em 14 discursos. Esse número representa aproximadamente $48,27 \%$ das vezes em que o Brasil foi citado e aproximadamente 63,63\% das citações à Argentina. Em relação as demais coocorrências, devem ser ressaltadas as citações que mencionaram a Nigéria juntamente com o Brasil (cinco coocorrências, representando aproximadamente 55,55\% das citações à Nigéria e 17,24\% das citações ao Brasil) e juntamente com a Argentina (quatro coocorrências, representando aproximadamente 44,44\% das citações à Nigéria e 18,18\% das citações à Argentina).

\subsection{Questões pontuais apontadas como relevantes}

A última dimensão de análise é a de outras questões que foram apresentadas pelos representantes estatais como relevantes nos processos políticos do Atlântico Sul. Essas questões se diferem das relações políticas já observadas, pois, enquanto as categorias de relações políticas abordam dinâmicas amplas e tratadas de modo geral, a presente categoria trata de questões específicas e pontuais, muitas vezes relacionadas a um número limitado de atores, mas que detém o potencial de impactar as dinâmicas regionais como um todo. A título de exemplo, enquanto tratar de "segurança cooperativa" sem entrar em especificidades seria identificado como parte da categoria "Questões de Segurança e Paz tratadas de modo geral", uma passagem que cita 
diretamente um conflito interno de um Estado específico será classificada dentro de uma categoria própria na dimensão de análise observada no momento.

Partindo da análise dos discursos que compõem a presente parcela do corpus da pesquisa, as seguintes categorias foram derivadas do texto:

(1) Apartheidna África do Sul, a qual engloba discursos que demonstram preocupação com o regime então vigente na África do Sul, os quais giram em torno principalmente de críticas às violações dos direitos humanos pelo regime de segregação racial então vigente no país, críticas à manutenção de controle ilegítimo sobre o território da Namíbia ${ }^{10}$ e preocupações em relação ao programa nuclear sul-africano, identificada pelo rótulo $\mathrm{E} 1$;

(2) Questão das Ilhas Falklands, arquipélago sob controle do Reino Unido sobre o qual a Argentina reivindica posse, tendo sido a razão direta para um conflito entre os dois Estados em 1982, identificada pelo rótulo E2;

(3) Conflito interno na Libéria, dividido oficialmente em duas guerras civis, com a primeira ocorrendo entre 1989 e 1997 e a segunda entre 1999 e 2003, identificada pelo rótulo E3;

(4) Conflito interno na Angola, guerra civil que oficialmente durou de 1975 até $2002^{11}$, identificada pelo rótulo E4;

(5) Conflito interno em Serra Leoa, guerra civil que oficialmente durou de 1991 até 2002, identificada pelo rótulo E5;

(6) Conflito interno na Guiné-Bissau, guerra civil que durou de junho de 1998 até maio de 1999, identificada pelo rótulo E6;

\footnotetext{
${ }^{10}$ O território da Namíbia (então ainda chamada de Sudoeste Africano) era um protetorado sul-africano desde o fim da Primeira Guerra Mundial, quando foi tomado das forças alemãs. A Guerra de independência da Namíbia teve início em 1966, quando tropas da Organização do Povo da África do Sudoeste (SWAPO) atacaram forças do exército sul-africano estacionadas no território. Ainda no ano de 1966, a Assembleia Geral da ONU revogou o mandato da África do Sul para gerenciar o território, colocando-o sob tutela da ONU, decisão que não foi reconhecida pela África do Sul, a qual continuou a exercer controle sobre o território até 1990, ano da independência da Namíbia (ver: Dreyer, 1994). Sendo a questão da independência da Namíbia indissociável da questão do regime do Apartheid sul-africano, a presente pesquisa optou por agrupá-las na mesma categoria.

${ }^{11} \mathrm{O}$ conflito se iniciou imediatamente após a descolonização angolana, sendo travado por antigos grupos de libertação do país, o Movimento Popular de Libertação de Angola (MPLA) e a União Nacional para a Independência Total de Angola (UNITA). O governo da África do Sul foi um dos maiores apoiadores da UNITA, fornecendo dinheiro, armas e tropas para lutar contra o governo angolano do MPLA (ver: Pearce, 2012), fato que, em alguns discursos, é apontado como uma agressão sul-africana contra a Angola. Apesar de estar relacionado à questão do Apartheid na África do Sul, optou-se por alocar a Guerra Civil Angolana em uma categoria distinta, tendo em vista que esta é uma questão que por si só envolve muitos outros atores e problemáticas.
} 
(7) E conflito interno na República Democrática do Congo, dividido oficialmente em duas guerras civis, com a primeira ocorrendo entre outubro de 1996 e maio de 1997 e a segunda entre agosto de 1998 e julho de 2003, identificada pelo rótulo E7.

O Gráfico 13 apresenta a evolução anual do volume de discursos com trechos que citam as problemáticas identificadas na presente dimensão de análise. Ressalta-se que cada discurso pode ter apresentado citação a mais de uma única questão, sendo, portanto, classificado em mais de uma única categoria. Adicionalmente, atenta-se para o fato de que os anos que não apresentaram discursos enquadrados em nenhuma das categorias da presente dimensão de análise foram excluídos da representação gráfica para facilitar a visualização.

GRÁFICO 13: EVOLUÇÃO ANUAL DAS PERCEPÇÕES MANIFESTAS EM RELAÇÃO AS QUESTÕES PONTUAIS APONTADAS COMO RELEVANTES NO ESPAÇO REGIONAL

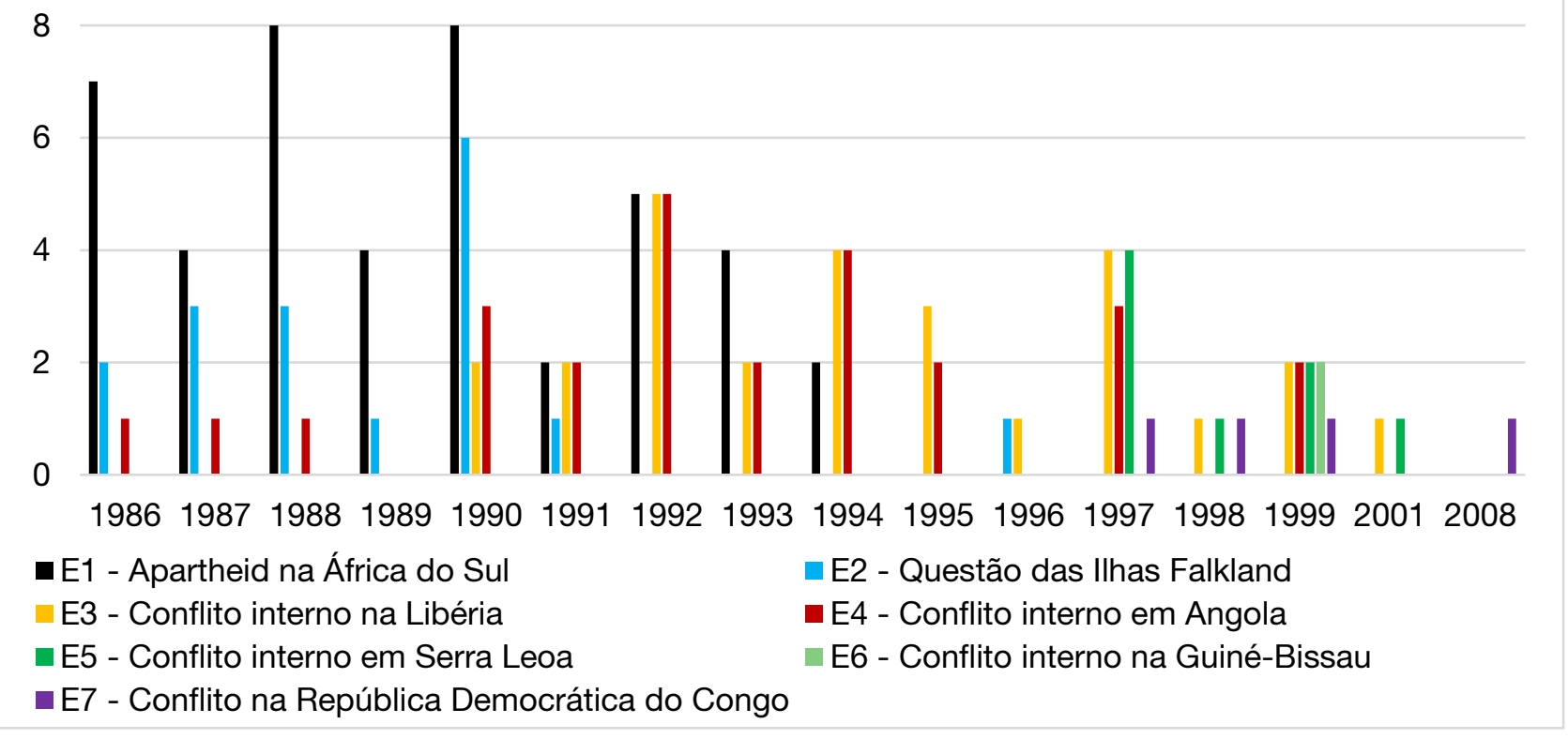

FONTE: Elaboração própria.

O primeiro fator a chamar a atenção na análise do Gráfico 13 é o volume de menções ao regime do Apartheid na África do Sul, citado em um total de 44 discursos entre os anos de $1986 \mathrm{e}$ 1994. Esses dados parecem ser um forte indício de que os esforços em torno da ZOPACAS foram, em grande parte, movidos pela percepção de ameaça proveniente do governo sul-africano, o qual, além da violação dos direitos humanos de seus próprios cidadãos através do regime de segregação racial então vigente no país, também manteve o controle ilegítimo sobre a Namíbia e tomou parte ativa na Guerra Civil Angolana, enquanto desenvolvia um programa nuclear com fins militares. Nesse mesmo período, outra pauta que apresentou relevância nos debates foi a questão das Ilhas Falklands, tema ativo, sobretudo, entre 1986 e 1991, acumulando ao todo 17 citações. 
O início da década de 1990 marcou a ascensão de duas novas pautas, ambas relacionadas a guerras civis em Estados-membros da ZOPACAS, tendo o conflito na Libéria sido citado 27 vezes e o conflito na Angola 26 vezes. Todas as demais pautas foram citadas menos de 10 vezes, com o conflito em Serra Leoa acumulando oito citações; o conflito na República Democrática do Congo acumulado quatro; e o conflito em Guiné-Bissau apenas duas citações, ambas em 1999.

Nesse sentido, o Gráfico 14 apresenta de modo detalhado como cada Estado se manifestou no tocante as quatro categorias principais da presente dimensão de análise, isto é, o regime do Apartheid na África do Sul, a questão das Ilhas Falklands e os conflitos em Angola e Libéria. Dos 17 Estados a terem os discursos analisados na pesquisa, Camarões foi excluído do Gráfico 14, pois o único discurso proferido por seus representantes com o tema do Atlântico Sul não foi enquadrado em nenhuma das categorias analisadas.

\section{GRÁFICO 14: VOLUME TOTAL DE DISCURSOS REFERENCIANDO OUTRAS PAUTAS}

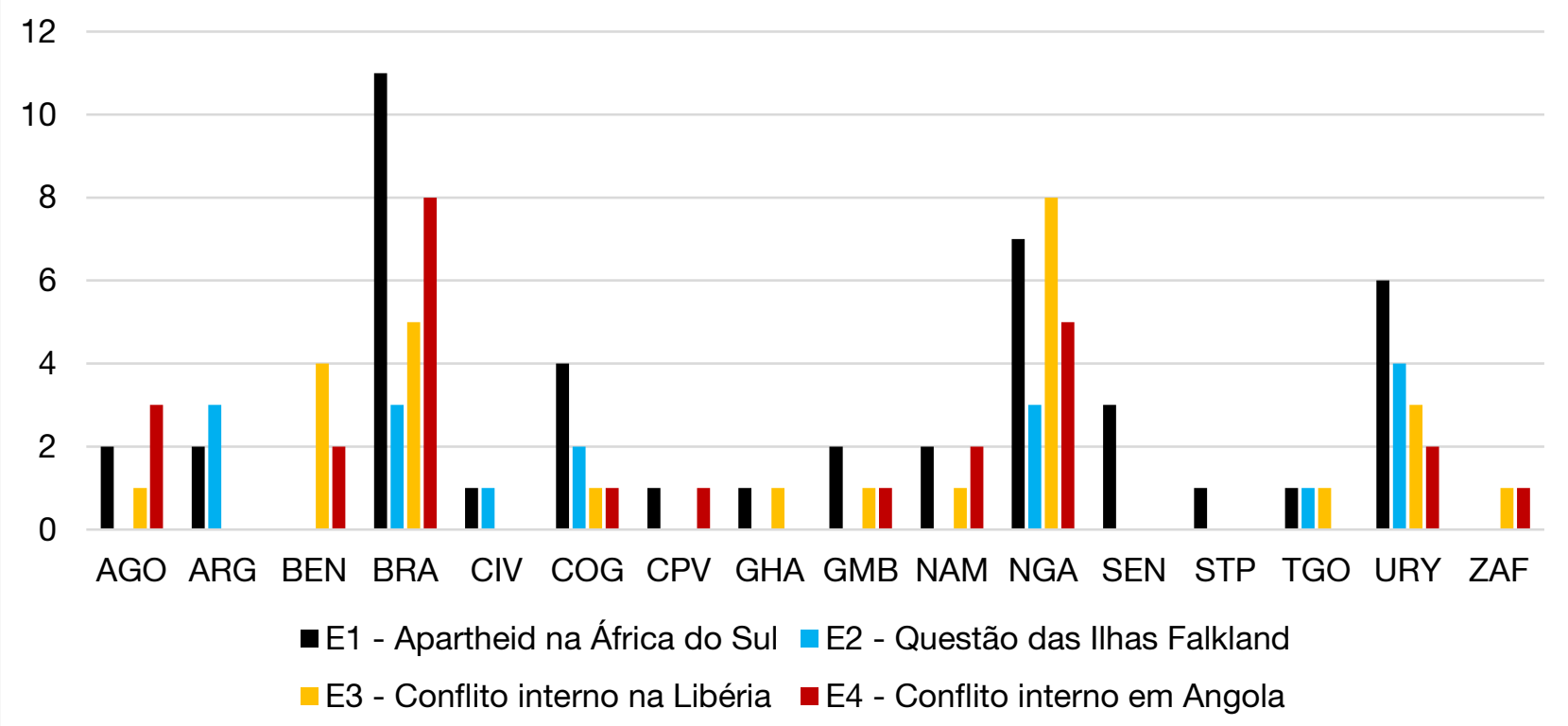

FONTE: Elaboração própria.

A análise do Gráfico 14 revela que a questão do Apartheid na África do Sul foi aquela cujo debate foi o mais intenso e bem distribuído entre os vários Estados, não tendo sido a pauta mencionada apenas pelo Benin e pela própria África do Sul. Nesta categoria, o Estado que mais se manifestou foi o Brasil, registrando 11 menções ao tema, número muito superior ao de Angola e Namíbia (com duas menções cada), Estados estes que foram diretamente afetados pelas ações sul-africanas. Contudo, esse valor é, em parte, justificado ao se considerar a disparidade do volume total de discursos dos três Estados no período. 
Os dados sobre a questão das Ilhas Falklands são talvez os mais interessantes nessa etapa da análise. Ao contrário do esperado, a Argentina se manifestou relativamente pouco sobre o assunto, abordando-o em apenas três discursos (aproximadamente 23,07\% do seu total de discursos registrados), número até mesmo superado pelas menções ao tema feitas pelo Uruguai, com quatro menções (aproximadamente $30,76 \%$ do seu total) ${ }^{12}$. Brasil e Nigéria, os dois Estados com o maior número de discursos, igualmente se manifestaram sobre o tema três vezes cada. Esses dados sugerem a existência de certa solidariedade regional à reivindicação argentina sobre o território, mas que parece ser muito limitada no ambiente da AGNU. É possível ainda que esse apoio seja mascarado nos discursos que propagam a necessidade política dos Estados sulatlânticos se unirem contra ingerências externas, mas o volume de dados nessa categoria foi igualmente baixo, sendo citada em apenas 20 discursos, dos quais sete apresentaram coocorrência com a questão específica das Ilhas Falklands.

Finalmente, a questão das guerras civis em Angola e Libéria foram abordadas em algum ponto pela maior parte dos Estados observados, com uma maior importância dada a um ou outro dos conflitos variando de caso a caso. Em ambos os casos, os Estados que mais se manifestaram foram Brasil e Nigéria, com o Brasil se manifestando oito vezes em relação à Guerra Civil Angolana (o que é justificado nos próprios discursos pela proximidade cultural enquanto dois países lusófonos) e cinco vezes em relação ao conflito na Libéria. No caso nigeriano estes números se invertem, com os representantes do Estado africano se manifestando cinco vezes em relação à Guerra Civil Angolana e oito em relação ao conflito na Libéria.

\section{CONSIDERAÇÕES FINAIS}

O estudo aqui apresentado teve como objetivo tentar compreender como se deu a evolução do pensamento expresso pelos Estados banhados pelo Atlântico Sul no tocante ao caráter regional do território oceânico em questão. Para tanto, foram observados os discursos proferidos pelos representantes desses países na Assembleia Geral das Nações Unidas que citassem nomeadamente o Atlântico Sul, produzindo uma análise diacronica que contemplou três décadas de produção discursiva.

Dentro do recorte temporal contemplado pela pesquisa, foi possível identificar três períodos distintos. O primeiro e mais ativo deles se estende do surgimento da ZOPACAS, em 1986, até a Reunião Ministerial de Buenos Aires, ocorrida em 1998. Nos anos iniciais, a agenda política associada ao Atlântico Sul foi um produto direto de sua época, com os tópicos mais relevantes

\footnotetext{
${ }^{12}$ Vale relembrar que a Argentina e o Uruguai registraram o mesmo volume total de discursos sobre o Atlântico Sul na Assembleia Geral da ONU no período, com cada um se manifestando um total de 13 vezes.
} 
estando associados à percepção de ameaça advinda do cenário de confrontação das duas superpotências no fim da Guerra Fria e, talvez mais importante, do regime sul-africano, que além da manutenção do regime do Apartheid, ocupava o território da Namíbia, influenciava a Guerra Civil Angolana e desenvolvia um programa nuclear com fins militares, o que fundalmentalmente ia contra a ideia de uma Zona de Paz livre de armas nucleares no Atlântico Sul.

Com o fim da Guerra Fria em 1991, e do regime do Apartheid sul-africano em 1994, as pautas que compunham o centro da agenda política da ZOPACAS foram superadas, iniciando o desligamento da iniciativa. Embora os Estados patrocinadores da Zona - com destaque especial ao Brasil - tenham procurado atualizar o interesse de seus pares pelo Atlântico Sul através da inserção de novas pautas no debate, como a proteção aos recursos naturais e o combate ao tráfico de drogas e armas, essas não parecem ter despertado real engajamento. Como consequência, entre os anos de 1994 e 1998 o interesse pelo Atlântico Sul e pela ZOPACAS foi pouco a pouco se reduzindo, resultando, enfim, em um período de inatividade entre os anos de 1999 e 2007. Embora a iniciativa tenha sido retomada em 2007, os debates na AGNU se mantiveram vagarosos e sem grande relevância. Ainda que seja possível que os debates sobre o Atlântico Sul tenham sido movidos para outras arenas discursivas, há de se notar que a escolha mais provável seriam as próprias Reuniões Ministeriais da ZOPACAS, as quais parecem ter entrado em um novo perído de inatividade após a última reunião, ocorrida em 2013 em Montevidéu. Ademais, o baixo número de discursos na AGNU localizados após 2007, sobretudo em comparação com o volume notado até 1998 e incluindo a completa ausência de discursos após 2015, não deixa de ser sugestivo.

Por fim, retornamos a pergunta que guiou a pesquisa aqui apresentada: o Atlântico é entendido como uma região pelos Estados por ele banhados?

Dos 106 discursos analisados, proferidos por representantes de 17 Estados ao longo de três décadas, 92 discursos apresentaram alguma menção à delimitação geográfica do Atlântico Sul enquanto uma região. Desses, 39 discursos (42,39\% do total) apontaram o Atlântico Sul como sendo um mero espaço de interação entre a América do Sul e a África - ou seja, uma não-região -, com essa posição se fortalecendo a partir do ano de 1995. Essa percepção se faz presente até mesmo entre os Estados que são os maiores defensores históricos do projeto, com 38,09\% dos discursos brasileiros sendo enquadrados nessa categoria. Assim, se o papel de um region-builder é convencer os demais atores que determinado espaço territorial é uma região, os poucos Estados que se interessaram em apoiar um projeto de construção regional para o Atlântico Sul parecem não ter tido sucesso nem mesmo no nível mais básico: convencer a si mesmos.

* Artigo recebido em 09 de novembro de 2019, aprovado em 18 de dezembro de 2019. 


\section{REFERENCIAS}

ABDENUR, A. E.; SOUZA NETO, D. M. DE. O Brasil e a cooperação em defesa: a construção de uma identidade regional no Atlântico Sul. Revista Brasileira de Politica Internacional, v. 57, n. 1, p. 5-21, 2014.

AGUILAR, L. C. Atlântico Sul: as relações do Brasil com os Países Africanos no Campo da Segurança e Defesa. Austral: Revista Brasileira de Estratégia e Relações Internacionais, v. 2, n. 4, p. 49-71, 2013.

AMORIM, S. G. DE. Perspectivas Brasileiras na Convergência entre o SISBIN e a ZOPACAS. Austral: Revista Brasileira de Estratégia e Relações Internacionais, v. 2, n. 4, p. 11-31, 2013.

ANDERSON, B. Imagined Communities: Reflections on the Origin and Spread of Nationalism. Revised ed. Londres: Verso, 1983.

BARBOSA, L. C. P. A Zona de Paz e Cooperação do Atlântico Sul (ZOPACAS): Criação, projeção e dimensão político-estratégica. 2015. 193 p. Dissertação (Mestrado em Estudos Estratégicos Internacionais) - Faculdade de Ciências Econômicas da Universidade Federal do Rio Grande do Sul, Porto Alegre, 2015.

BARDIN, L. Análise de Conteúdo. São Paulo: Edições 70, 2011.

BRASIL. UN General Assembly Forty-ninth session - Agenda item 30: Zone of peace and cooperation of the South Atlantic. 1994. Disponível em: <https://digitallibrary.un.org/record/167685? In=en>. Acesso em: 18 dez. 2019.

BUZAN, B.; WÆVVER, O. Regions and Powers: The Structure of International Security. Cambridge: Cambridge University Press, 2003.

BUZAN, B.; WÆVER, O.; WILDE, J. DE. Security: A New Framework for Analysis. Boulder: Lynne Rienner Publishers, 1998.

CAMPOS, C. Método de análise de conteúdo: ferramenta para a análise de dados qualitativos no campo da saúde. Rev. Bras. Enferm., v. 57, n. 5, p. 611-614, 2004.

CARVALHO, T. L. DE; SOUZA, A. L. F. R. DE. A Institucionalização no Complexo Regional de Segurança Sul-Americano: uma comparação entre quatro períodos históricos. Revista Brasileira de Estudos de Defesa, v. 5, n. 1, p. 303-327, 2019.

DREYER, R. F. Namibia and Southern Africa: Regional Dynamics of Decolonization, 1945-90. [s.I.] Kegan Paul International, 1994. 
ESPACH, R. Reflections onthe Ends, Ways, and Means of Maritime Security Cooperation in the South Atlantic. In: DUARTE, É.; BARROS, M. C. DE (Eds.). Maritime Security Challenges in the South Atlantic. Londres: Palgrave Macmillan, 2019. p. 129-153.

FERNANDES, J. H. C. A Soberania Cibernética na Zona de Paz e Cooperação do Atlântico Sul. In: GHELLER, G. F.; GONZALES, S. L. DE M.; MELO, L. P. DE (Eds.). Amazônia e Atlântico Sul, desafios e perspectivas para a defesa no Brasil. Brasília: Ipea, 2015.

HALPERIN, S.; HEATH, O. Political Research - Methods and Practical Skills. Oxford: Oxford University Press, 2012.

NEUMANN, I. B. A Region-Building Approach to Northern Europe. Review of International Studies, v. 20 , n. 1 , p. $53-74,1994$.

A Region-Building Approach. In: SÖDERBAUM, F.; SHAW, T. M. (Eds.). Theories of New Regionalism. Londres: Palgrave Macmillan, 2003.

NOVELLI, D. H.; PEREIRA, A. E. What makes a region: establishing analytical dimensions for the application of Neumann's Region-Building Approach. Revista Brasileira de Informação Bibliográfica em Ciências Sociais -BIB/ANPOCS, v. 2019, n. 89, p. 1-28, 2019.

OLIVEIRA, D. C. Análise de conteúdo temático-categorial: uma proposta de sistematização. Revista de Enfermagem UFRJ, v. 16, n. 4, p. 569-576, 2008.

PEARCE, J. Control, politics and identity in the Angolan civil war. African Affairs, v. 111, n. 444, p. 442-465, 2012.

PIMENTEL, C. R. O ressurgimento da ZOPACAS e a agenda de segurança no Atlântico Sul. Tensões Mundiais, v. 12, n. 22, p. 113-143, 2016.

TASSINARI, F. Mare Europaeum: Baltic Sea Region Security and Cooperation from post-Wall to post-Enlargement Europe. Copenhagen: University of Copenhagen, 2004.

VAZ, C. A. M.; MIGON, E. X. F. G. O Brasil e as alternativas para o incremento da cooperação em Segurança \& Defesa na Zona de Paz e Cooperação do Atlântico Sul (ZOPACAS). Revista da Escola Superior de Guerra, v. 28, n. 56, p. 110-131, 2013.

VIEGAS FILHO, J. A Segurança do Atlântico Sul e as Relações com a África. Brasília: FUNAG, 2016.

WIESEBRON, M. Amazônia Azul: Pensando a Defesa do Território Marítimo. Austral: Revista Brasileira de Estratégia e Relações Internacionais, v. 2, n. 3, p. 107-131, 2013. 